\title{
A Bra Monitoring System Using a Miniaturized Wearable Ultra-Wideband MIMO Antenna for Breast Cancer Imaging
}

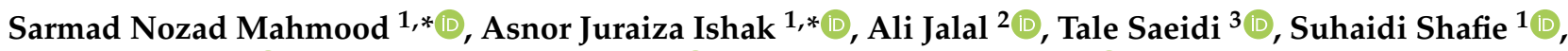 \\ Azura Che Soh ${ }^{1} \mathbb{1}$, Muhammad Ali Imran ${ }^{4,5} \mathbb{D}^{-}$and Qammer H. Abbasi ${ }^{4} \mathbb{D}$
}

1 Department of Electrical and Electronic Engineering, Faculty of Engineering, Universiti Putra Malaysia, Serdang 43400, Malaysia; suhaidi@upm.edu.my (S.S.); azuracs@upm.edu.my (A.C.S.)

2 College of Information Engineering, Al-Nahrain University, Al-Jadriya Complex, Baghdad 10070, Iraq; ali.sadeq@coie-nahrain.edu.iq

3 Electrical and Electronic Engineering Department, Universiti Teknologi Petronas, Bandar Seri Iskandar 32610, Malaysia; tale_g03470@utp.edu.my

4 Communications Sensing and Imaging Group, James Watt School of Engineering, University of Glasgow, Scotland G12 8QQ, UK; muhammad.imran@glasgow.ac.uk (M.A.I.); Qammer.Abbasi@glasgow.ac.uk (Q.H.A.)

5 Artificial Intelligence Research Centre (AIRC), University of Ajman, Ajman 346, United Arab Emirates

* Correspondence: gs53389@student.upm.edu.my (S.N.M.); asnorji@upm.edu.my (A.J.I.)

\section{check for} updates

Citation: Mahmood, S.N.; Ishak, A.J.; Jalal, A.; Saeidi, T.; Shafie, S.; Soh, A.C.; Imran, M.A.; Abbasi, Q.H. A Bra Monitoring System Using a Miniaturized Wearable Ultra-Wideband MIMO Antenna for Breast Cancer Imaging. Electronics 2021, 10, 2563. https://doi.org/ 10.3390 /electronics10212563

Academic Editor: Dimitra I. Kaklamani

Received: 13 August 2021

Accepted: 14 October 2021

Published: 20 October 2021

Publisher's Note: MDPI stays neutral with regard to jurisdictional claims in published maps and institutional affiliations.

Copyright: (c) 2021 by the authors. Licensee MDPI, Basel, Switzerland. This article is an open access article distributed under the terms and conditions of the Creative Commons Attribution (CC BY) license (https:// creativecommons.org/licenses/by/ $4.0 /)$.

\begin{abstract}
This paper represents a miniaturized, dual-polarized, multiple input-multiple output (MIMO) wearable antenna. A vertically polarized, leaf-shaped antenna and a horizontally polarized, tree-shaped antenna are designed, and the performance of each antenna is investigated. After designing the MIMO antenna, it is loaded with stubs, parasitic spiral, and shorting pins to reduce the coupling effects and remove the unwanted resonances. Afterward, the two-port MIMO cells are spaced by $2 \mathrm{~mm}$ and rotated by $90^{\circ}$ to create three more cells. The antennas are designed using two layers of denim and felt substrates with dielectric constants of 1.2 and 1.8, and thicknesses of $0.5 \mathrm{~mm}$ and $0.9 \mathrm{~mm}$, respectively, along with the ShieldIt ${ }^{\mathrm{TM}}$ conductive textile. The antenna covers a bandwidth of $4.8-30 \mathrm{GHz}$ when the specific absorption rate (SAR) meets the $1 \mathrm{~g}$ and $10 \mathrm{~g}$ standards. Isolation greater than $18 \mathrm{~dB}$ was obtained and mutual coupling was reduced after integrating shorting pins and spiral parasitic loadings. A maximum radiation efficiency and directive gain of $96 \%$ and $5.72 \mathrm{dBi}$ were obtained, respectively, with the relatively small size of $11 \times 11 \times 1.4 \mathrm{~mm}^{3}$ for the single element and final dimensions of $24 \times 24 \times 1.4 \mathrm{~mm}^{3}$ for the full assembly. The antenna's performance was examined for both on-body (breast) and free space conditions using near-field microwave imaging. The achieved results such as high fidelity, low SAR, and accuracy in localization of the tumour indicate that the MIMO antenna is a decent candidate for breast cancer imaging.
\end{abstract}

Keywords: MIMO antenna; breast cancer; antipodal Vivaldi antennas; microwave imaging

\section{Introduction}

A miniaturized MIMO antenna working for both WBAN and breast cancer imaging is presented. A group of wireless sensors with special specifications as un-bulky, hight, low power, small dimensions can be considered in a WBAN system to screen human body conditions as well as the encompassing environment. In the field of health care, where they allow personal data tracking, WBANs play a critical role. They are a hot topic in health and disease control science, along with tracking of human physiological behaviours including health statuses [1]. A lightweight ultra-low-power wearable WBAN sensors are considered as off-body, on-body, or in-body sensors. Both electromagnetic coupling and RF (radio frequency) communication can be used to communicate wirelessly between these sensors. Wearable devices have been utilized to monitor a range of conditions of a human body [2]. Wearable antennas can be applied as a feature of WBAN structures to transmit and receive signals to the human body, such as in a shoelace or wearable bra that checks 
for tumours in a woman's breasts. The patient will not need to go to the hospital if this wearable bra is part of a WBAN system. This is especially helpful in situations such as the current COVID-19 pandemic. UWB antennas are also useful in the microwave imaging (MWI) of breast cancer. This method of imaging can be a substitute to other methods such as X-ray mammography and is advantageous because it involves no harmful radiation and no pressurised imaging. This allows for more frequent imaging, which is essential for detecting tumours early.

Designing antennas for use near the human body presents several problems, including the consequences of high loss and tissue permittivity [3]. A wearable antenna usually works when it encounters a human body's high dielectric constant, which has an effect on the design's radiation characteristics [4]. As a result, when the antenna comes into contact with the body, its output suffers. As a result, antennas must be carefully engineered to preserve efficiency when they come into contact with an environment other than air [5]. Moreover, wearable structures should adhere to precise absorption rate requirements (SARs). In body area network (BAN) applications, many planar structures have been applied [6-9].

When flexible and wearable antennas bend and stretch during usage, it affects the wearable antennas' radiation characteristics, which is particularly important when circular polarization is needed. Wearable antennas are subjected to a variety of crumpling and bending conditions by their very nature [10]. Additionally, for multi-band or dual-band applications, these effects must be managed, and output must be consistent across bending conditions to make sure that the working bands do not suffer dramatically [11]. Flexible wearable antennas need a considerable degree of bending (up to 90 degrees) [12]. When antennas are meant to work near the body, they should be designed and not to significantly alter their radiation characteristics $[6,12,13]$. The antenna can be more stable and less influenced by bending when its measurements are small $[14,15]$. To enhance the wearable antennas' efficiency, miniaturization has been a key factor.

One of the most significant advances in increasing bandwidth has been the use of multiple antennas in multiple input-multiple output (MIMO) technology and 5G connectivity. Via diversity and spatial multiplexing, MIMO antennas can be used to improve communication capability. Massive MIMO and antenna beamforming can boost signal to noise ratio (SNR) and decrease consumption of power, particularly in small and portable devices with a small battery $[16,17]$. Furthermore, the efficiency of antenna radiation has a physical limit. The key challenge in small antenna design is to overcome their low radiation efficiency.

Among multiple antennas, mutual coupling effect (can be shown as $\mathrm{S}_{\mathrm{n} 1}$ ) is a considerable factor in antenna array design and is another challenge in MIMO system implementation. The electromagnetic waves emitted by one antenna interfere with the electromagnetic waves emitted by neighbouring antennas when several antennas are close together (as in compact devices). This mutual coupling impact distorts the radiation pattern of antennas, alters antenna's impedance matching, all of which led to a decrement in MIMO device power $[18,19]$. Furthermore, the metasurface isolation technique used by [20] to increase the isolation and reduce the coupling effects. A wideband antenna was designed with low sidelobe [21] and inter-port isolation to reduce the coupling [22]. Apart from these findings, vast decoupling technique were revised in [23].

In a MIMO device, reciprocal coupling between antenna elements is unavoidable, and this has a negative impact on the antenna's characteristics. Generally, when designing an antenna array, the space between antenna elements must be at least $\lambda_{0} / 2$ to ensure good performance. Balancing compactness with performance is the key to designing a MIMO antenna array. Placing multiple antennas in a limited space results in a strong coupling between antenna elements. The smaller the antenna element space, the stronger the mutual coupling. This mutual coupling will cause the antenna elements' current to change, which will deteriorate the antenna's performance. For example, when array 1 is excited to generate electromagnetic waves, a part of energy is directly radiated into free space, and another part of energy is coupled into the adjacent antenna. After receiving energy, 
antenna generates current and radiates a part of energy into space again. Another part of antenna's energy enters the signal source and is superimposed with the energy generated by antenna 2, which causes the antenna to be mismatched, thereby deteriorating the antenna array's performance. The mutual coupling of antennas will change the input impedance of antenna elements, thus causing mismatch in the antenna array. Only well-matched antennas can better radiate energy into free space. If antennas are not matched, this causes power reflection to the source, resulting in power loss. At the same time, mutual coupling will cause radiation pattern distortion, low radiation efficiency, and increased correlation between MIMO antenna elements. Therefore, it becomes very important to reduce the mutual coupling between antennas and improve the array antenna's performance. Isolation, an important indicator of antenna performance, is a parameter that must be considered when designing an antenna array [24].

In MIMO and array antennas, decoupling techniques suppress reciprocal coupling (and boost isolation). To meet the communication system's requirements, high level of stability and lower half power beamwidth are favoured [25]. There are many strategies for reducing reciprocal coupling, including the use of neutralisation lines [26,27], the inclusion of parasitic elements [28], and decomposition techniques [29-31]. All these methods are inefficient in MIMO systems and may not be appropriate for massive MIMO systems (They showed some drawbacks in terms of the MIMO antenna performances and how the decoupling technique could not improve the coupling and isolation efficiently). MIMO antennas were used to be created in a single mode which had lower gain, date rate transmission, and narrower BW [17].

There are only a few ultra-wideband (UWB) MIMO antennas specifically designed for breast cancer imaging. With dimensions of $20 \mathrm{~mm} \times 20 \mathrm{~mm}$, a wideband antenna was built on a transparent polyimide substrate $\left(\varepsilon_{r}=3.5-3.8\right)$ and achieved $3 \mathrm{GHz} \mathrm{BW}$. It was then placed inside a bra to detect a tumour in breast tissue [32,33]. The system's narrow bandwidth prevented it from accurately detecting the tumour, and many clutters appeared around it. Some versatile wearable antennas for $5 \mathrm{G}$ and IoT applications have been developed [34-40]. Ultra-wideband signal-based techniques have recently attracted a lot of attention [41-43]. This application also uses the MIMO technique [44]. An ultrawideband signal is transmitted and received by an electrically switched array in [45]. To approximate the return in a specific volumetric pixel, measurements are time aligned. Ultra-wideband MIMO is directly addressed in [46], and it is used to detect tumours. A MIMO antenna with a BW of $2.3-12.2 \mathrm{GHz}$ and dimensions of $70 \times 35 \mathrm{~mm}^{2}$ for tumour detection in breast tissue [41]. In [46] a changed array transmits and receives wideband signals. The ultra-wideband MIMO concepts used in the identification of tumours are briefly discussed in [46]. Therefore, the construction of a circular, fractal-shaped transmitter with a size of $60 \times 100 \mathrm{~mm}^{2}$ and an ultra-wide BW of $3.1-12.0 \mathrm{GHz}$ is detailed in this paper [47]. It also includes a human interface MIMO UWB antenna operated with a BW of 3.1-11.2 GHz and dimensions of $36 \times 22 \times 1.6 \mathrm{~mm}^{3}$ [48]. In addition to the works above, more studies designed UWB MIMO antennas [49-51].

This paper has four sections. First, in Section 1, we present a comprehensive introduction of recent papers discussing MIMO antennas for both imaging and communication, their underlying technology, and related challenges. Then, the proposed wearable MIMO UWB antenna, its design, and the investigation of its performance are detailed in Section 2. The study's findings are summarized in Section 3. Finally, in Section 4, we present our closing remarks.

\section{Design of the MIMO UWB Antenna}

When designing a lightweight, miniaturized, wearable UWB MIMO antenna, a substrate with a high dielectric constant and low loss tangent should be used. To ensure excellent coupling between the antenna and the breast, the dielectric constant of the flexible antenna's substrate better to be similar to the relative permittivity of the breast $[3,52]$. After designing a traditional patch and enhancing gain and BW with techniques such as 
using two layers with different dielectric constants, the proposed antenna was developed (Figure 1). Thicker substrate gives more gain and efficiency, multiband possibility, and the fringing fields were suppressed by the shorting pins loading. The characteristics of a leaf-shaped monopole patch antenna and a tree-shaped line antenna were first evaluated. These two antennas were merged into one. The antenna was then loaded with stubs, a parasitic spiral, and shorting pins to boost the MIMO antenna's characteristics and reduce mutual coupling effects, resulting in increased gain and radiation efficiency. In all steps of designing the antenna, the dimensions of the patch, the stubs, and loadings were optimised to obtain the best results. Figure 2 and Table 1 show the measurement setup and the parameters of the antenna design.

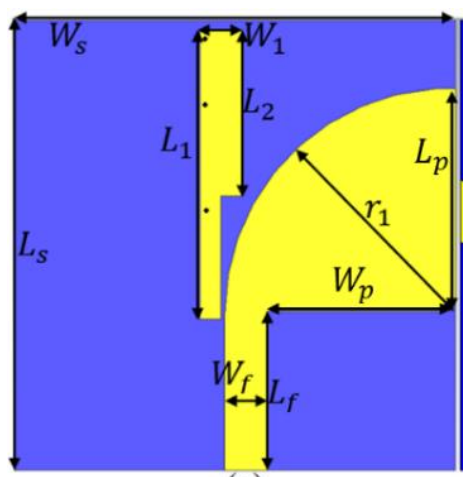

(a)

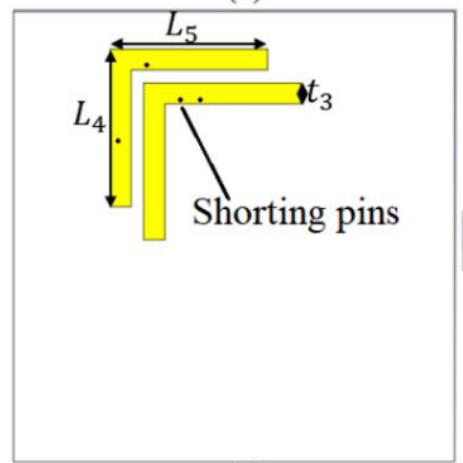

(c)

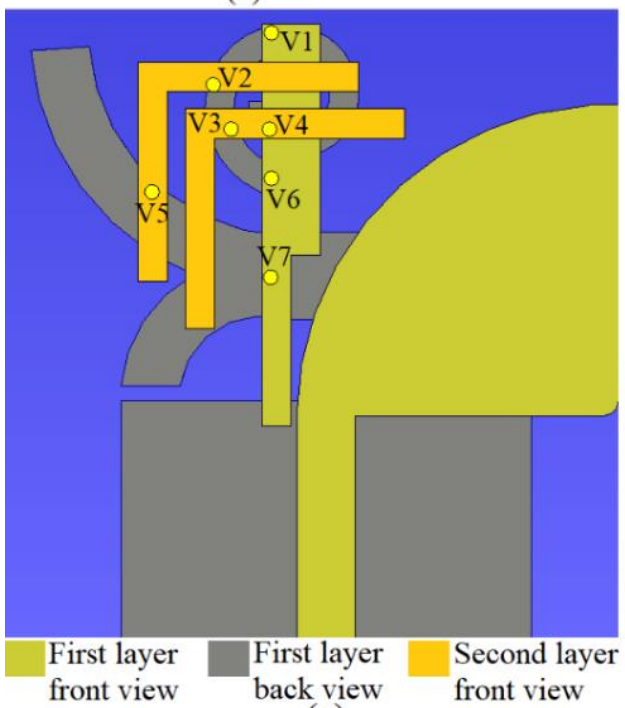

(e)

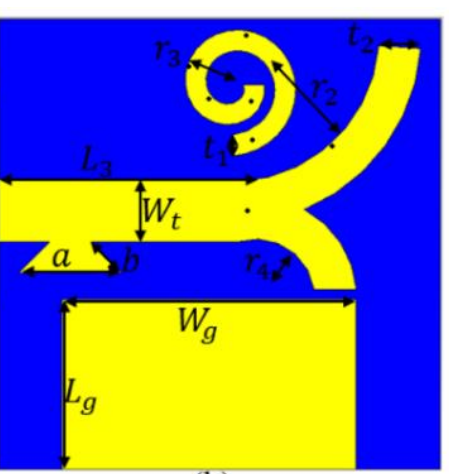

(b)
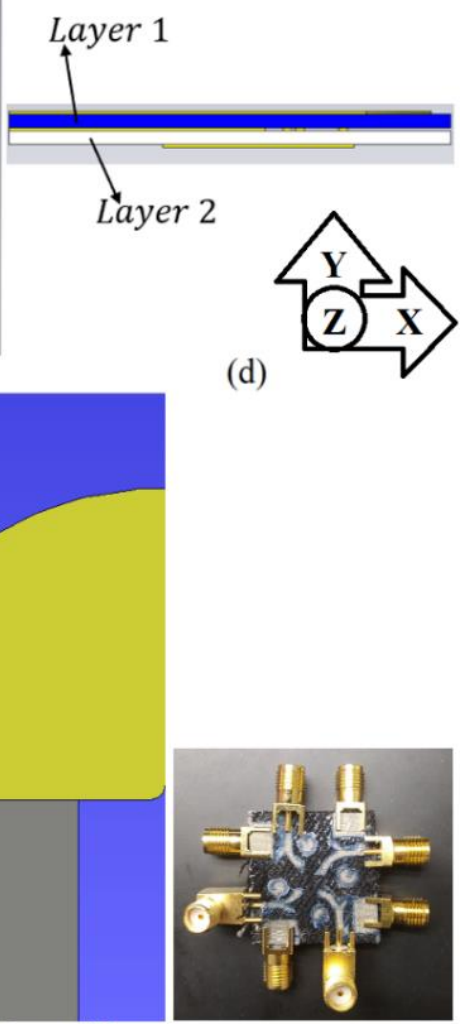

(f)

Figure 1. (a) Front view of the first layer, (b) back view of the first layer, (c) front view of the second layer, (d) side view of the antenna, (e) overlap prototype of the antenna with all layers $\left(\mathrm{V}_{1-7}\right.$ are the shorting pins), and (f) the fabricated antenna. 


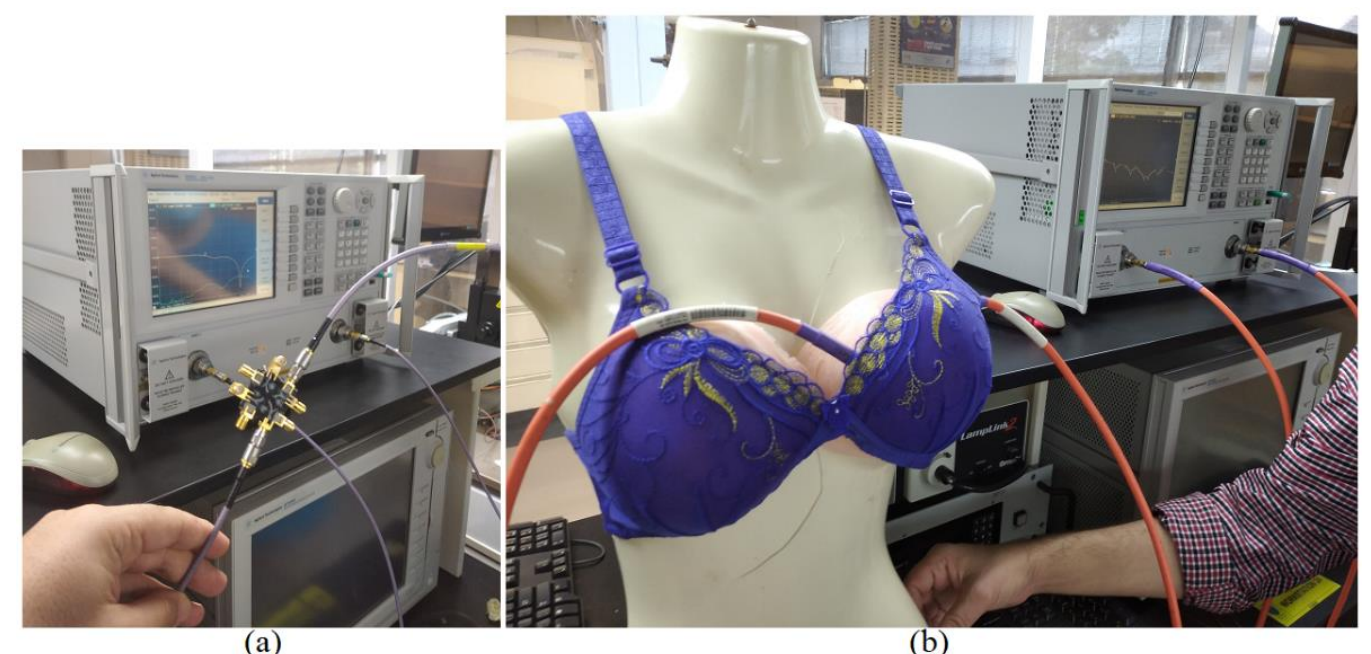

(a)

(b)

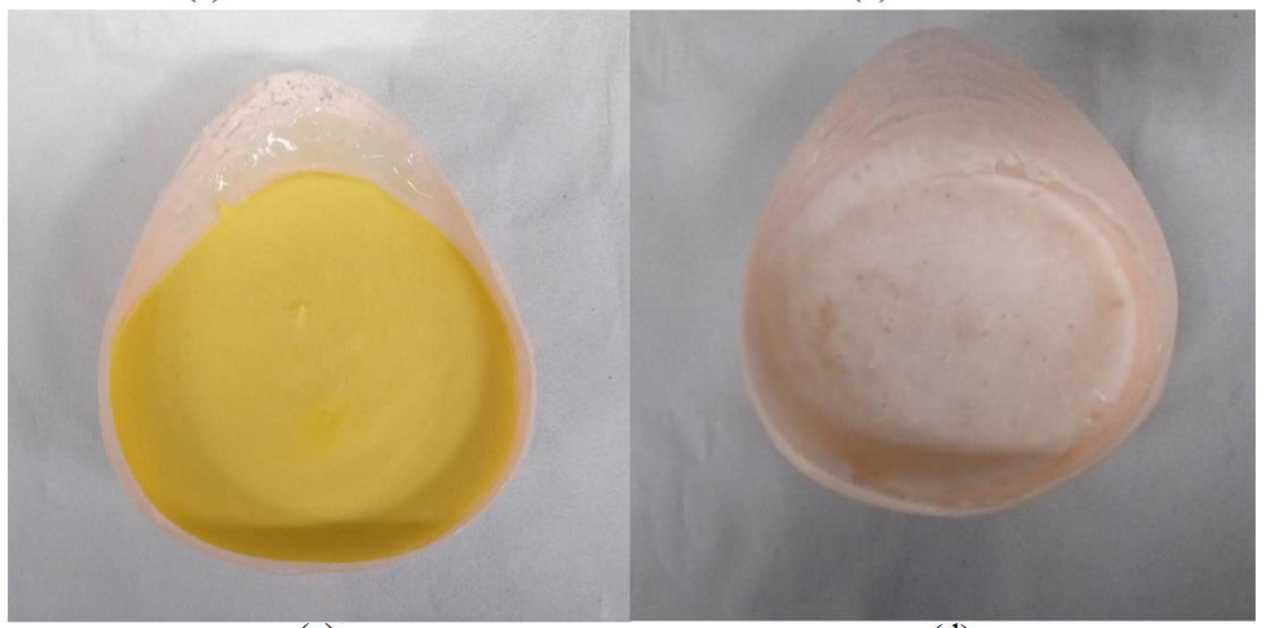

(c)

(d)

Figure 2. (a) measurement setup in air, (b) measurement on bra, and (c) fabricated bra phantom filled with a fabricated breast fat, skin, and tumour and (d) fabricated bra filled with fabricated skin.

Table 1. Antenna parameters dimensions (param: parameters).

\begin{tabular}{cccccc}
\hline Param $(\mathbf{m m})$ & Dimensions & Param $(\mathbf{m m})$ & Dimensions & Param $(\mathbf{m m})$ & Dimensions \\
\hline$W_{s}$ & 11 & $W_{1}$ & 1 & $W_{g}$ & 7 \\
$L_{s}$ & 11 & $W_{t}$ & 1.5 & $L_{g}$ & 4 \\
$W_{f}$ & 1 & $a$ & 1.03 & $r_{3}, t_{1}$ & $1,0.5$ \\
$L_{f}$ & 3.8 & $b$ & 2.5 & $r_{4}, t_{3}$ & $0.25,0.5$ \\
$r_{1}$ & 3.5 & $r_{2}, t_{2}$ & $1.75,1$ & $L_{5}$ & 3.75 \\
$L_{1}$ & 6.88 & $L_{2}$ & 3.92 & $L_{3}$ & 5.7 \\
$L_{4}$ & 3.75 & & & & \\
\hline
\end{tabular}

Design Configuration of the Antennas

Figure 2a depicts the measurement setup of the proposed MIMO antenna with eight ports (the planned two-port MIMO antenna's four array components were incorporated). When the MIMO antenna encountered the breast, the scattering data were recorded by a vector network analyser (VNA). Afterward, the data were extracted from the VNA and imported to a PC to reconstruct the image of the breast tumour using an algorithm. Figure $2 b, c$ indicate the measurements of the bra phantom with a diameter and height of $100 \mathrm{~mm}$ and $50 \mathrm{~mm}$, respectively (it should be mentioned that the SMA ports are connected to the conductive textile with silver epoxy conductive glue). Using the heat soldering with these miniaturized dimensions and conductive textile is very difficult. This phantom was 3D printed using an elastic Polylactic Acid (PLA) $\left(\varepsilon_{r} \cong 1.45\right)$ material and was 
almost equivalent to a size $E$ female breast. It should be mentioned that the antenna was sewn on the shirt to prevent movement during the measurement. Moreover, the relative permittivity $\left(\varepsilon_{r}\right)$ and conductivity $(\sigma)$ of the skin, breast fat, and tumour are presented in Table 2. The antenna configuration might look complicated because it was attempted with a miniaturised antenna with higher isolation and lower coupling. Therefore, several loadings are employed to achieve that.

Table 2. Materials' relative permittivity and conductivity.

\begin{tabular}{ccc}
\hline Parameter & $\varepsilon_{r}$ & $\sigma$ \\
\hline Breast fat & 5.62 & $0.1301 \pm 0.068$ \\
Skin & 43 & 0.0007 \\
Tumour & 57 & $2.7 \pm 0.07$ \\
\hline
\end{tabular}

The antenna was composed of a leaf-shaped patch fed by a transmission line on one side. The tree-shaped line antenna on the other side is fed through a transmission line to achieve circular polarisation and enhance the directional pattern. The branches of this tree have different width than the feed line and offers better matching. Figure 1 and Table 1 depict the antenna arrangement and dimensions. It was created using a felt substrate with a dielectric constant of $\varepsilon_{r}=1.2$, a loss tangent of tan $=0.0009$, and a thickness of $\mathrm{h}=0.5 \mathrm{~mm}$. The thickness of the substrate is one factor which can affect the antenna's efficiency. Unwanted modes are triggered when it is too high. Excitation of these undesirable modes causes the directional pattern to be distorted and the degree of crosspolarisation to rise. As a result, a thin substrate with a low dielectric constant is favoured. The electrical length of the radiating leaf-shaped patch can be optimized to determine the phase difference of the travelling-wave currents. As a result, the antenna's lower and higher cut-off frequencies are determined by the electrical duration of this patch [53,54]. In [35-37], they recommended dielectric lens, artificial materials, and parasitic patch, respectively. A leaf shape patch resembling an antipodal shape on one side and tree shape line at the other side are presented. CST Microwave Studio (CST MWS), a full-wave electromagnetic simulation program, was used to design and test the antenna. The finite integration technique is used by CST MWS (FIT). The reason behind the choosing such bandwidth $(4.8-30 \mathrm{GHz})$ is first to cover FCC UWB-required BW and second to cover higher bands to have better accuracy in image reconstruction. A wider BW and higher frequency offer better image quality [55].

It should be mentioned that when the monopoles are used a significant portion of energy is radiated into surroundings, characteristics are rather complicated and mutual coupling is stronger. Due to these facts that might affect the antenna performance regarding detection of tumour in a breast media, the proposed antenna designed to be more directive with wider beam width. Moreover, the mutual coupling between two ports of a single MIMO cell (two-port cell) and each MIMO array in Figures 18 and 21 prove that the mutual coupling does not degrade the antenna performance dramatically since the S21 is less than $-18 \mathrm{~dB}$ at most of the working BW. Apart from those, the coaxial model and an antenna model do not have much difference at low frequency for low dielectric loss materials but have a little difference at high frequency for high dielectric loss materials. The antenna model can be suitable for the measurement for the materials with small discrepancy in dielectric constant over the entire frequency band.

A model of the proposed leaf-shaped antenna (inspired by AVA antenna and its high directional gain) combined with a planar tree-shaped line antenna is shown in Figure 1 [38]. The initial dimensions of a traditional AVA were altered after it was engineered and simulated to function at 3.8 GHz. Using the equations in [56,57], the exponential curve of leaf shape patch and the angle were calculated. The angle $\alpha$ and the patch and feed line lengths, $L_{p}, L_{f}, W_{f}$ and $W_{p}$, are the antenna's initial design parameters, as shown in Figure 1. After that, a stub was placed next to the leaf-shaped patch on the antenna to convert the stopband at $11.5 \mathrm{GHz}$ to a transfer band. The loading of the antenna and its 
effects on the reduction in mutual coupling, cross-polarization, and achieving a 50-input impedance will be explained later.

A transmission line (a combination of a straight transmission line and two exponential lines with radii of $r_{2}=4.5 \mathrm{~mm}$ and $r_{4}=1.25 \mathrm{~mm}$ ) and widths of $W_{t}$ and $t_{2}$ were used to feed the second planar tree-shaped line antenna built on the same substrate. The parasitic spiral loading provided circular polarization, reduced mutual coupling, and allowed for a large BW while keeping the antenna small [56]. With a width of $\mathrm{t}_{1}=0.5 \mathrm{~mm}, \mathrm{n}=1.75$ turns, an inner area of $0.5 \mathrm{~mm}$, and a space of $0.5 \mathrm{~mm}$, the parasitic spiral load was designed. To avoid increasing surface wave, an antenna's gap and width should be carefully constructed. After that, a balloon was attached to the tree-shaped antenna to increase its impedance BW and matching impedance. The two antennas (Antenna 1, the leaf-shaped patch, and Antenna 2, the tree-shaped line) were combined to form one antenna capable of acting as a dual-polarised antenna with two operating modes after they were optimized to obtain the necessary resonance frequencies.

During the optimisation of the design of the antenna, the size of each design parameter was altered to investigate the effects on the characteristics of the antenna, such as surface current distribution (SCD), as shown in Figure 3. Figure 3 shows the surface current density at the central frequency for the proposed Antenna 1 and Antenna 2. The effects of changes in the spacing, the radius, and the optimised dimensions were investigated by looking at the surface current distribution (SCD) at the frequencies are favoured. Each change altered the SCD of the antenna, as well as the electromagnetic field around it.

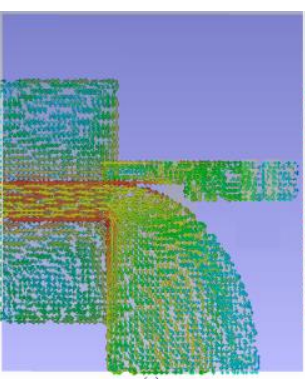

(a)

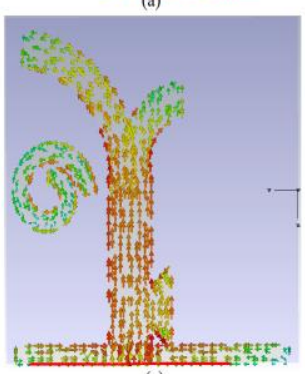

(e)

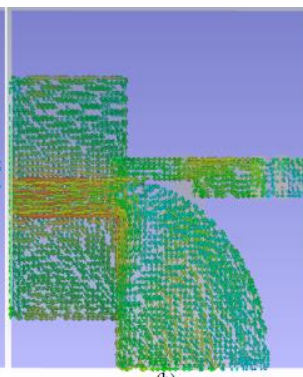

(b)

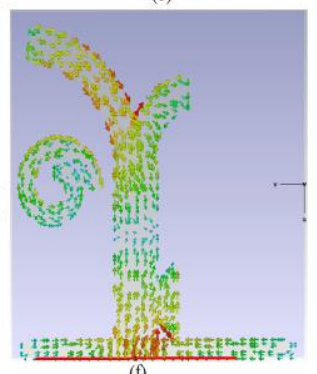

(f)

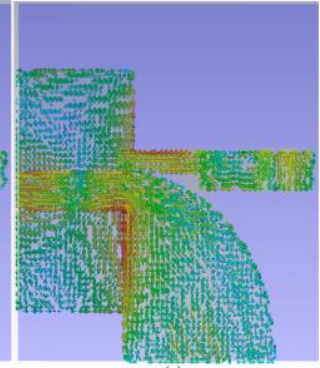

(c)

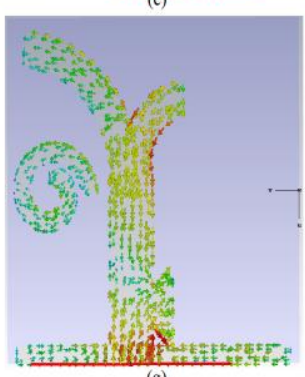

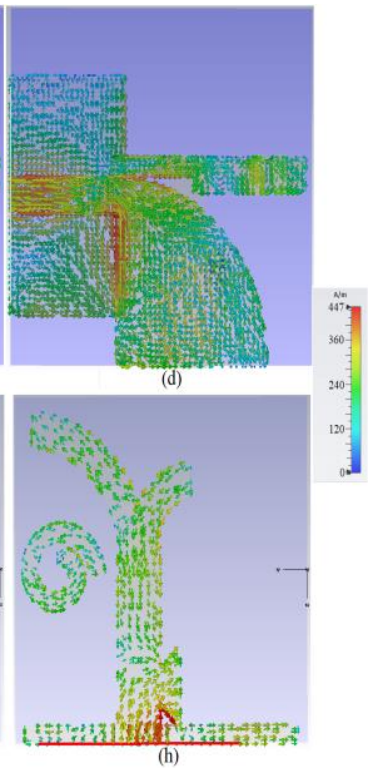

Figure 3. The SCD for Antenna 1 and Antenna 2 with loadings $((\mathbf{a}, \mathbf{e})$ at $6.2 \mathrm{GHz},(\mathbf{b}, \mathbf{f})$ at $15 \mathrm{GHz}$, $(\mathbf{c}, \mathbf{g})$ at $20 \mathrm{GHz},(\mathbf{d}, \mathbf{h})$ at $27 \mathrm{GHz})$.

The magnitude of the surface current was greatest on the truncated ground adjacent to the transmission line for Antenna 1, thus the stub with two different lengths and widths serves as an inductance to inhibit surface waves and mutual coupling. Antenna 2, on the other hand, had the most current around the straight line and balloon at $6.2 \mathrm{GHz}$, as well as around the other two exponential transmission lines at $15 \mathrm{GHz}$ and $20 \mathrm{GHz}$. Figure 3 also shows that for Antenna 1, the SCD was stronger around the feeding line, the ground, and the leaf-shaped area, while for Antenna 2, it was denser around the spiral at $6.2 \mathrm{GHz}$.

The parametric studies of both Antenna 1 and Antenna 2 before loading are presented in Figures 4 and 5, respectively. Two important factors affecting Antenna 2 are the length and width of the straight line $\left(L_{3}\right.$ and $\left.W_{t}\right)$. It is demonstrated that an increase in length of the straight line shifts the working BW to lower frequencies and enhances the BW. As the 
width of the straight line increases, the matching and impedance BW of the antenna are affected. Therefore, it should be optimised to obtain the perfect operating BW.

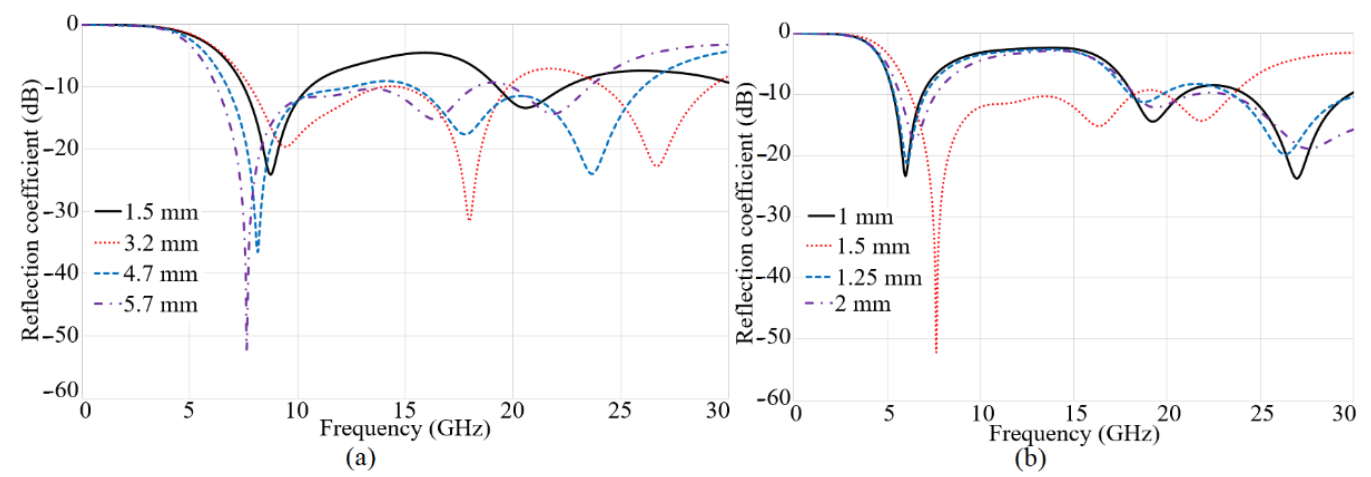

Figure 4. Parametric study of Antenna 1 (a) $L_{3}$ and (b) $W_{t}$ (before loading).

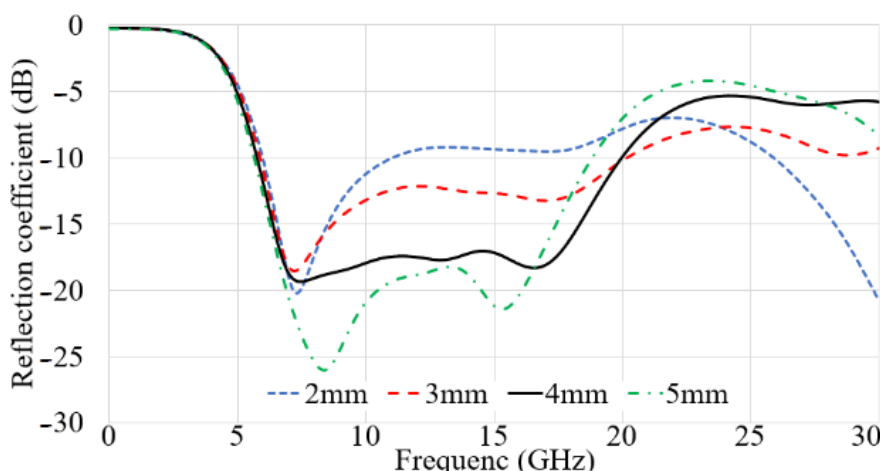

(a)

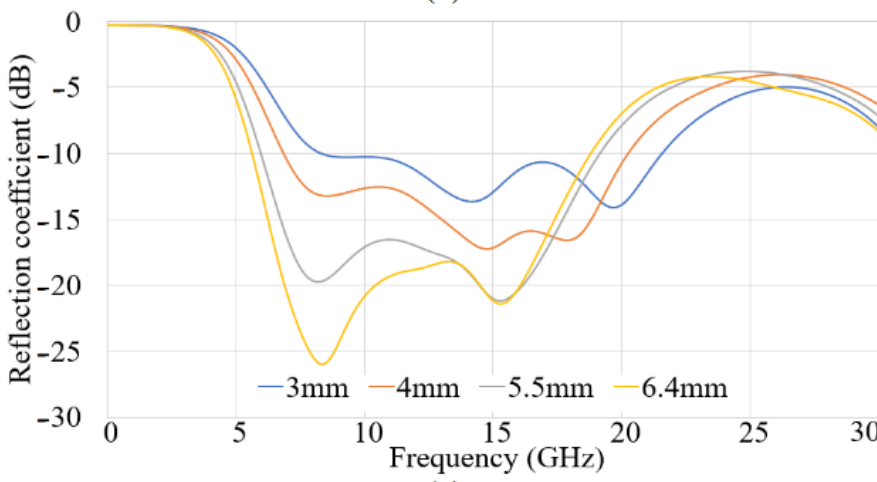

(c)

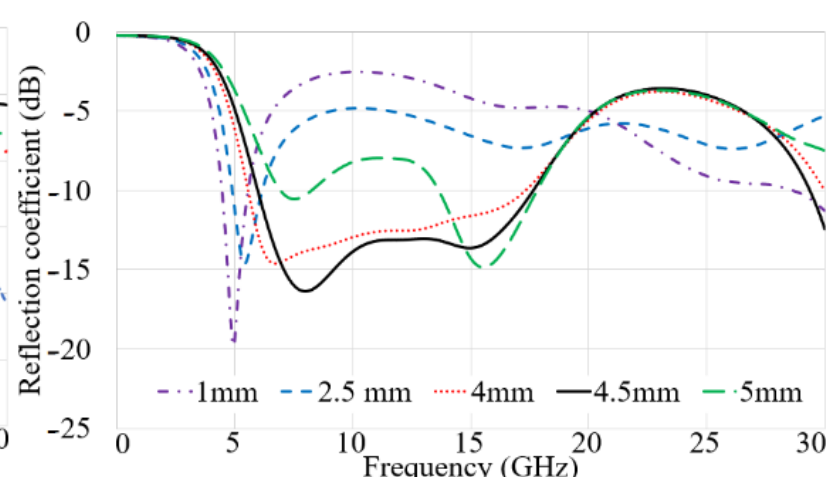

(b)

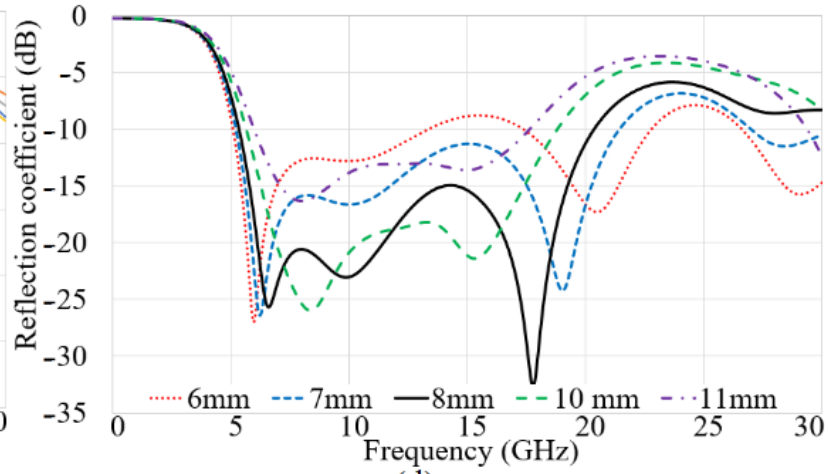

(d)

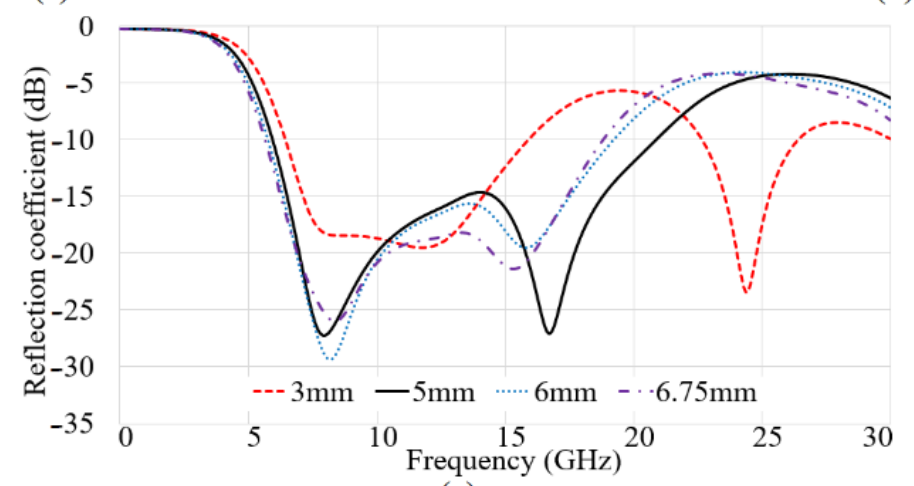

(e)

Figure 5. Parametric study of Antenna 2 (a) $L_{f},(\mathbf{b}) L_{g},(\mathbf{c}) L_{p},(\mathbf{d}) W_{g}$, and (e) $W_{p}$ (before loading). 
Figure 5 shows the parametric study of Antenna 1. The most effective parameters governing the performance of Antenna 1 are the dimensions of the ground, the patch, and the feed line. The length of the feed line $\left(L_{f}\right)$ modifies the BW and increases the value of the higher end of the operating BW. Unlike the feed line length, the ground length $\left(L_{g}\right)$ should be somewhere near to the patch. Thus, it should be optimised not to be too close and/or too far from it to offer the acceptable working BW. The increase in patch length $\left(L_{p}\right)$ enhances the BW towards the lower end of the BW and shifts it to the lower band which is certain. The widths of both the patch and the ground $\left(W_{p}, W_{g}\right)$ widen the BW of the antenna. However, they should be optimised not to increase the undesired fringing fields and the edges of the antenna (no loading means that none of the loading such as stubs, spiral, and shorting pins applied).

After parametric studies of both Antenna 1 and Antenna 2, all parameters were optimised to obtain the widest possible BW. Figure 6 shows the final and optimised reflection coefficient results of both antennas for on and off body conditions. Antenna 1 and Antenna 2 were then incorporated to produce the recommended UWB dual-polarised antenna for use in WBAN communication applications and as part of a microwave imaging system for the human breast.

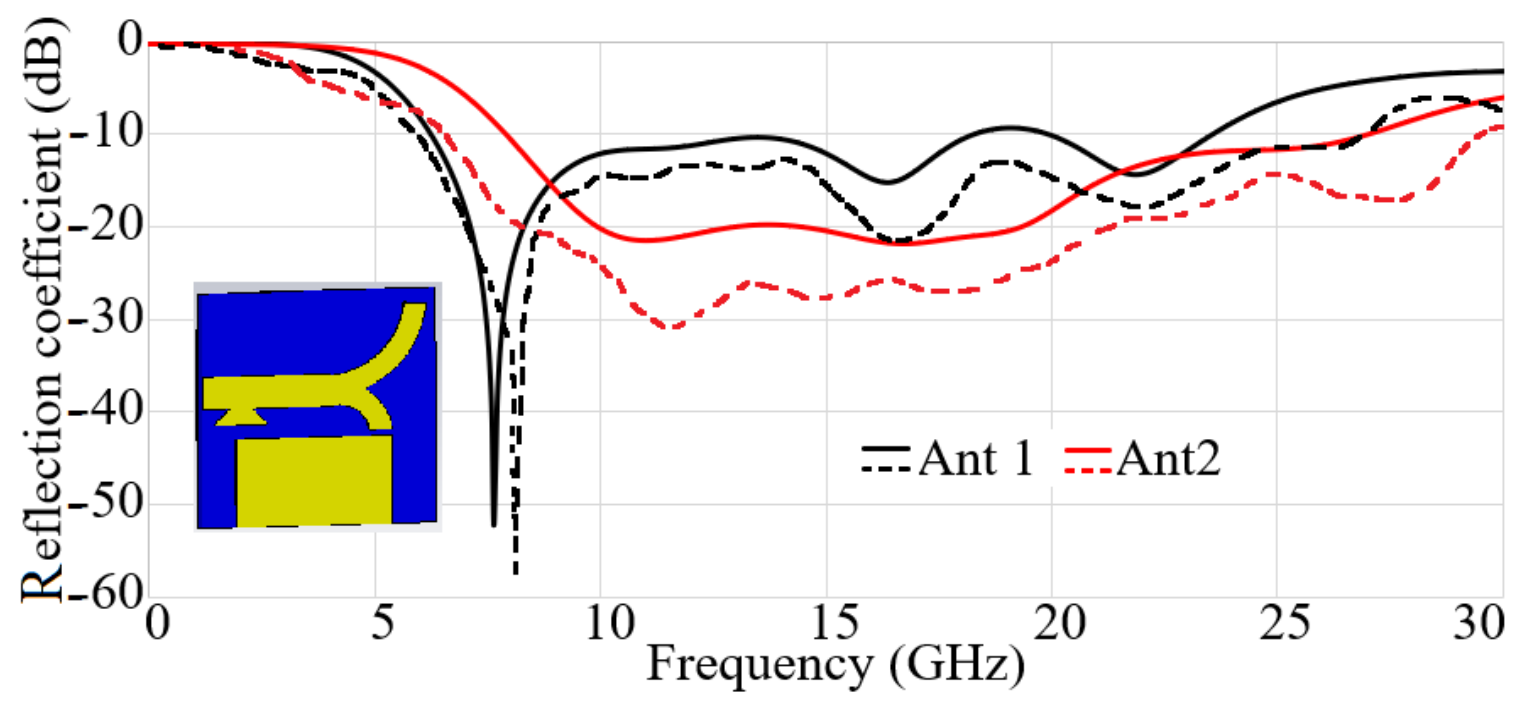

Figure 6. Reflection coefficient results for Antenna 1 (Ant 1) and Antenna 2 (Ant 2) without loading (off-body: dashed line, on-body: solid line).

Figure 7 shows how the fabrication tolerance affects the antenna's transmission and reflection coefficient results of the antenna (only for Ant 1 before integration with Ant 2). It will be informative to examine the antenna conditions after it is fabricated when the antenna using several loadings. In this figure, it is considered that the antenna's patch and ground are mislocating horizontally (hor) and vertically (ver) due to the fabrication errors, and then the results are recorded. It shows that the reflection and transmission coefficient results are not altered dramatically due to the fabrication errors, except for minor stopbands within the working BW.

A traditional monopole with a ground length of $\lambda / 8$ is commonly used in the design of wideband and UWB antennas. When designing a wearable UWB antenna, using a truncated ground greatly increases the antenna's SAR, which affects the antenna's efficiency and has negative, unacceptable effects on the body. As a result, to minimize the SAR value, the ground should be full. However, using a full ground prevents the antenna from operating in the wideband, rendering it a narrowband antenna. As a result, the MIM antenna was loaded to minimize mutual coupling and the SAR value, improving the antenna's characteristics. 


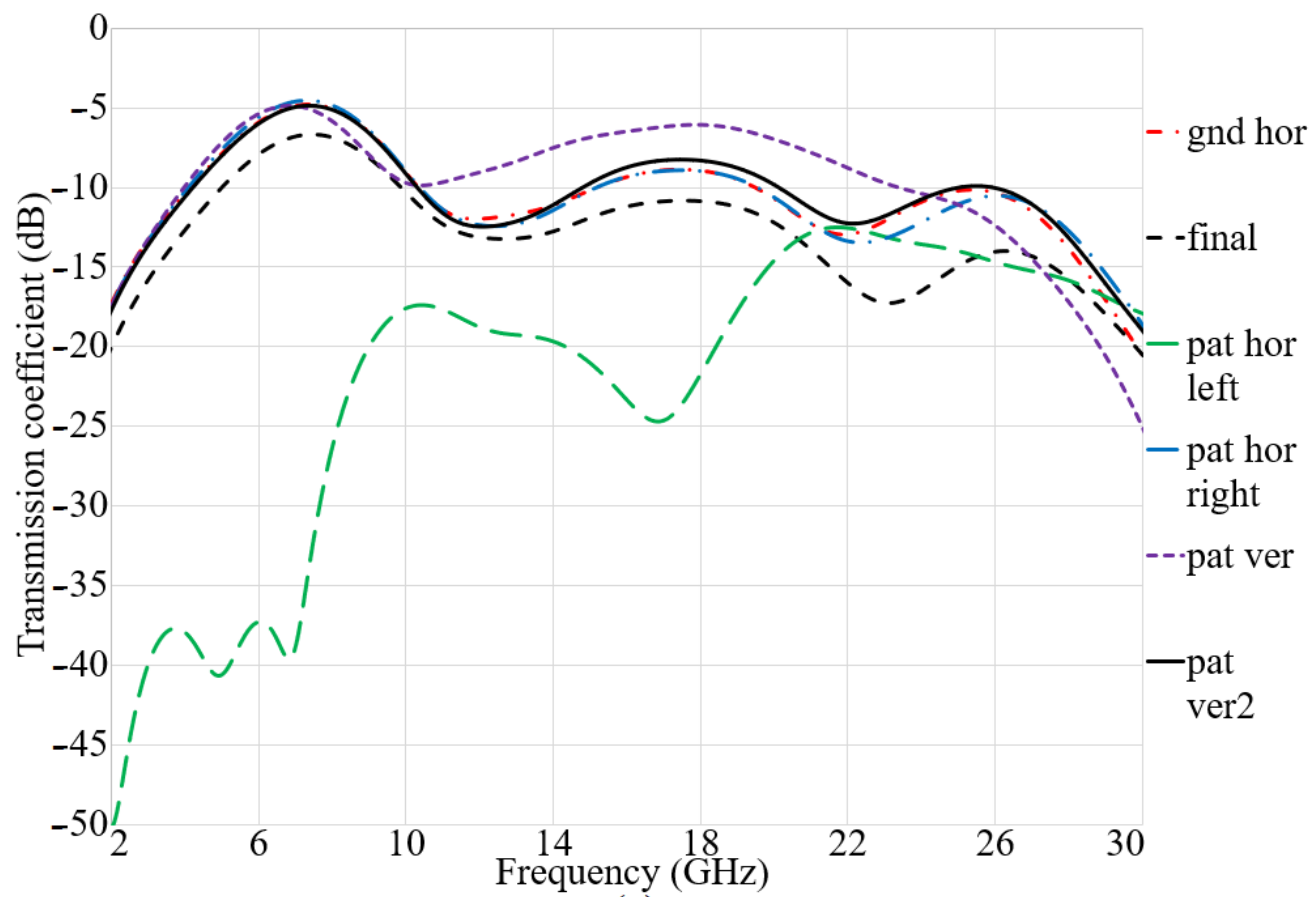

(a)

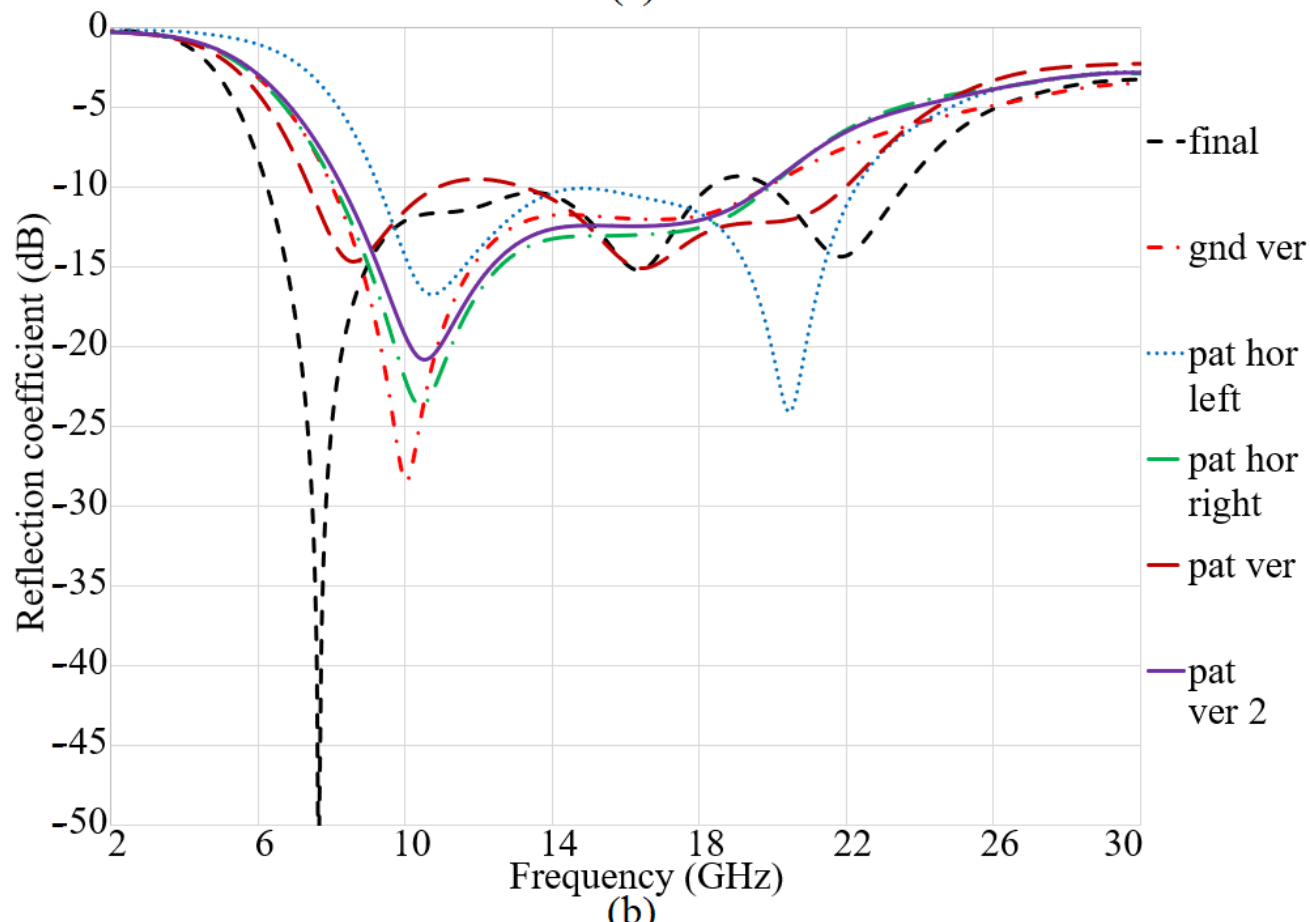

Figure 7. The fabrication tolerance effects on antenna results (a) transmission coefficient, (b) reflection coefficient.

\section{The MIMO Antenna for On-Body and Off-Body Conditions}

\subsection{MIMO Antenna's Radiation Characteristics}

The proposed antenna is a novel design using our proposed transmission technique and the equations presented in [15]. The antenna was made from flexible textile materials, with felt as the substrate (with a $\varepsilon_{r}=1.2$ and a $h=0.5 \mathrm{~mm}$ ) and ShieldIt ${ }^{\mathrm{TM}}$ as the conductor and/or resonator $(0.17 \mathrm{~mm})$. These materials were used to build Antenna 1 and Antenna 2. The antenna is loaded to reduce unwanted effects such as mutual coupling and the SAR value, as well as to increase the BW (shifting it to lower bands to have more penetration, 
thus more effects on tumour detection), radiation quality, and gain of the proposed two-port MIMO antenna that is used for imaging.

First, it is loaded with a long stub with two parts of different lengths and widths $\left(L_{1}, L_{2}, W_{1}\right)$. The whole working BW is shifted to a lower band (the lower end of the working BW is begun from $5.1 \mathrm{GHz}$ ) by applying this load. Moreover, this stub acts like switch-on on the UWB antenna structure which converts the stopbands at 5.1-6.7 GHz to passbands. It makes the unwanted surface currents near the path and the ground at the back to flow. However, adding this stub created a switch-off on the working BW at 8.5 GHz and 20.2-21.9 GHz. Afterward, it is loaded with a parasitic spiral shape on the other side to first create circular polarisation, swich on the stopbands at $8.5 \mathrm{GHz}$ and from 20.2 GHz to $21.9 \mathrm{GHz}$, and slightly shifts the band towards the lower frequency band. This also helped to reduce the mutual coupling effect and improve isolation by improving the $S_{21}$ level. Loading the antenna with the spiral structure switched off the UWB antenna's BW at approximately $10 \mathrm{GHz}$ (negligible, $-9.5 \mathrm{~dB}$ ) and $15 \mathrm{GHz}$ (this is due to the coupling capacitor that occurred because of the gap between the spiral and the strip line). To switch on these two stopbands, increase the MIMO antenna diversity, and improve the mutual coupling, the antenna loaded with shorting pins uses the surface current density of the antenna structure. It should be mentioned that the shorting pins $\left(\mathrm{V}_{1}\right.$ and $\left.\mathrm{V}_{6}\right)$ connect the wider part of stub to the spiral, and $V_{7}$ connects the narrower part of stub connected to the tree shape.

There was still room for improvement with respect to mutual coupling and isolation after the antenna was loaded with shorting pins. Therefore, a second layer of textile (denim) was applied to the antenna with a different $\varepsilon_{r}=1.8$ and $h=0.9 \mathrm{~mm}$ (on the leaf-shaped side). This layer was applied to increase the directivity pattern and prevent distortion by taking into account the antenna's radiation pattern. Two half-rectangular ring-shaped stubs were added to create a shift in the band towards the lower frequencies. Then, each of these stubs was loaded with shorting pins for further isolation improvement. The pins $\left(V_{2}\right.$ and $V_{3}$ ) connect the spiral to semi-rectangular rings on the second layer and $V_{5}$ connected the tree shape to the semi-rectangular ring on the second layer. The switch on and switch of statements are completely explained in [58,59].

Figure 8 indicates the S-parameter results of the single two-port MIMO antenna before loading with the stub, the parasitic spiral, and the shorting pins. It shows that the antenna's BW was significantly improved after loading. Furthermore, the mutual coupling and the isolation between the two ports were also improved. Both the lower and higher ends of the BW improved: from $6.2 \mathrm{GHz}$ before loading to $4.8 \mathrm{GHz}$ and from $27 \mathrm{GHz}$ to $30 \mathrm{GHz}$, respectively. The stop bands are removed completely, yet at $27 \mathrm{GHz}$ it is near $10 \mathrm{GHz}$, which is acceptable.

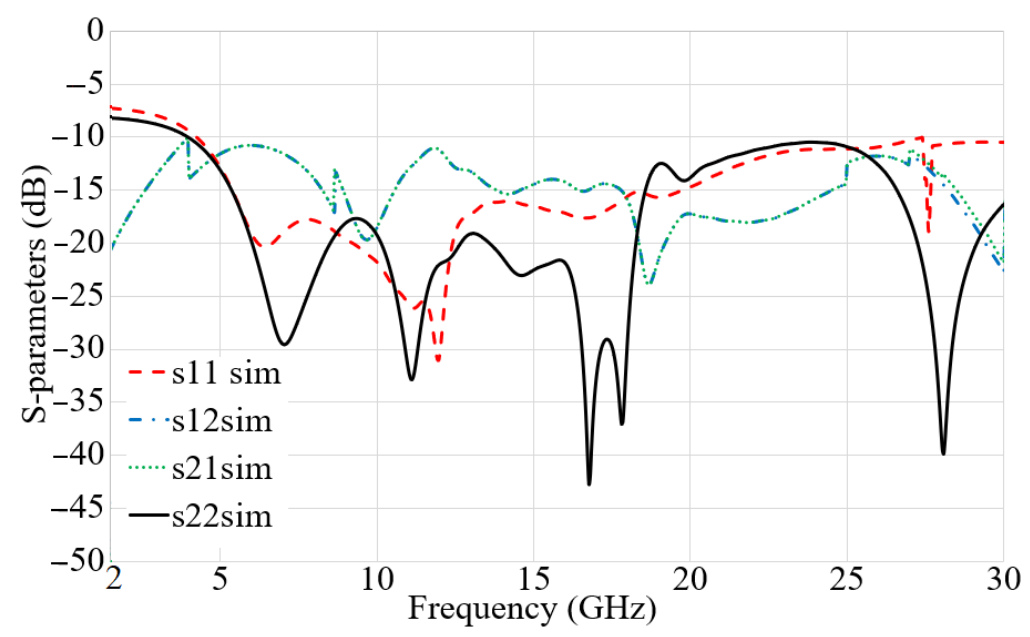

Figure 8. The S-parameter results for the single MIMO antenna (two ports) on-body without loading. 
Figure 9 shows the proposed antenna's simulated and measured reflection and transmission $\left(S_{11}, S_{21}\right)$ coefficients for both conditions. Figure 9 presents the results when the antenna utilizes the stub, spial, and the pins connected to the spiral only. Off-body refers to being outside of the body. When comparing the output of the antenna in free space and when it is near the body, the off-body condition should be taken into account. Air has a dielectric constant of one, which is very different from the dielectric constants of breast, skin, and tumour tissue. As a result, the antenna must be built and optimized in such a way that the S-parameters, radiation pattern, fidelity, and other designed factors described above do not change drastically with location. Figure 9 indicates that the working BW for on-body and off-body conditions did not vary significantly. As the antenna touched the body, however, the working BW was significantly decreased. All the resonances were measured, and there were only minor changes in working BW.

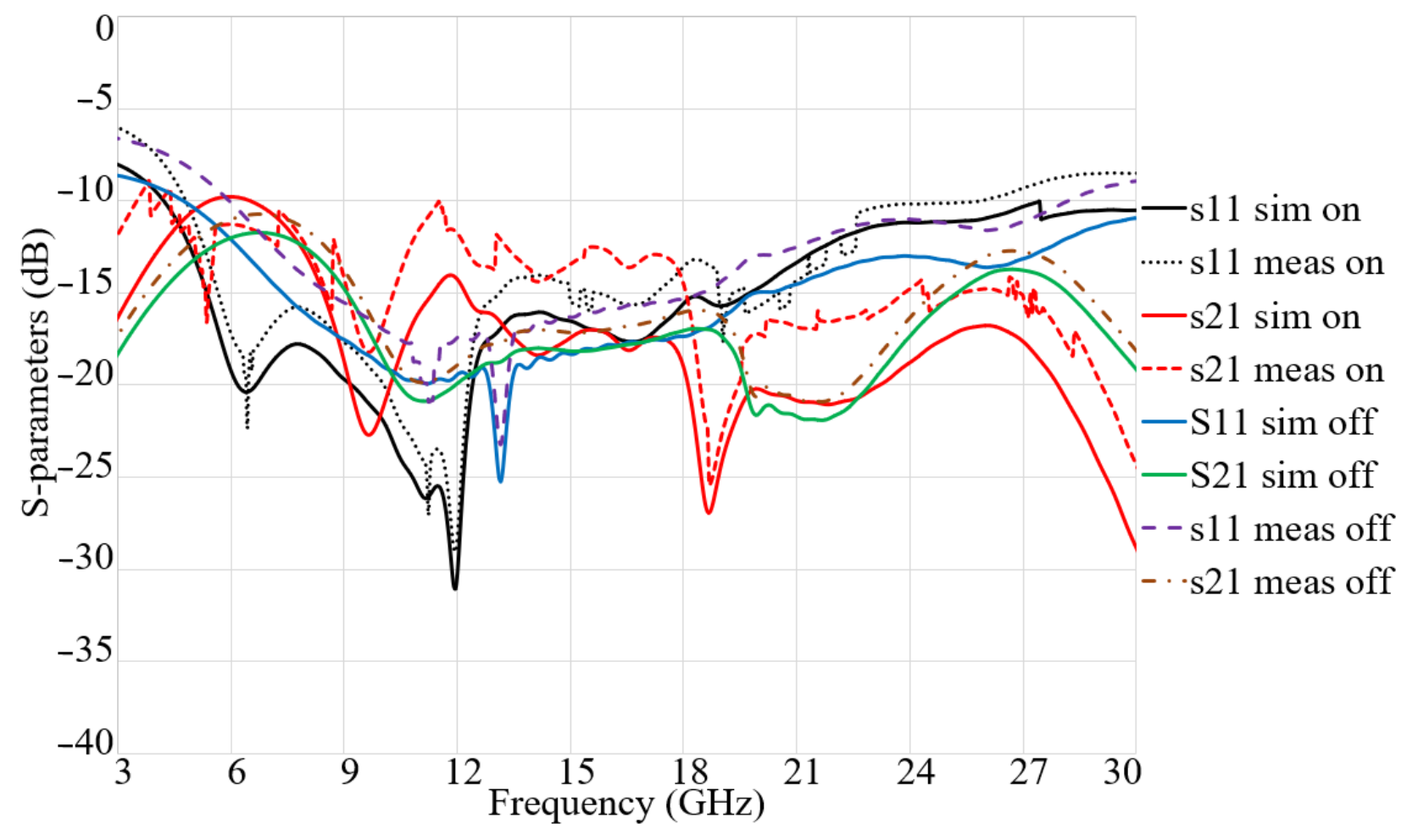

Figure 9. The S-parameters results for the proposed single MIMO antenna, on-body (on the breast phantom), and off-body (free space) for the simulation (sim) and measurements (meas) after adding pins to spiral.

Figure 10 depicts the simulated reflection coefficient result of the antenna after each stage of the loading for off-body. It is also illustrated that the stopbands in the BW converted to passband and the BW increased after each stage of loading. Figure 11 illustrates the reflection and transmission coefficients results of the antenna after all the loadings are added. It shows that good agreements exist among the simulation and measurement results. Moreover, the mutual cooling is reduced by more than $-8 \mathrm{~dB}$ at most of the working BW after adding the spiral and the shorting pins as expected. Authors in [60-63] used similar techniques for coupling reduction.

Following the loadings, Figure 12 indicates the antenna's surface current distribution. It helped with proper loading, particularly with the addition of the shorting pins. Since having a stable radiation pattern is critical when designing an antenna for image restoration, the antenna's radiation pattern should also be investigated. Figure 13 depicts the antenna's simulated co-polarization and cross-polarization radiation patterns at frequency bands, as well as the highest and lowest limits of the operating BW. Furthermore, it demonstrates that the radiation patterns did not vary by more than 10 degrees at different frequencies. 


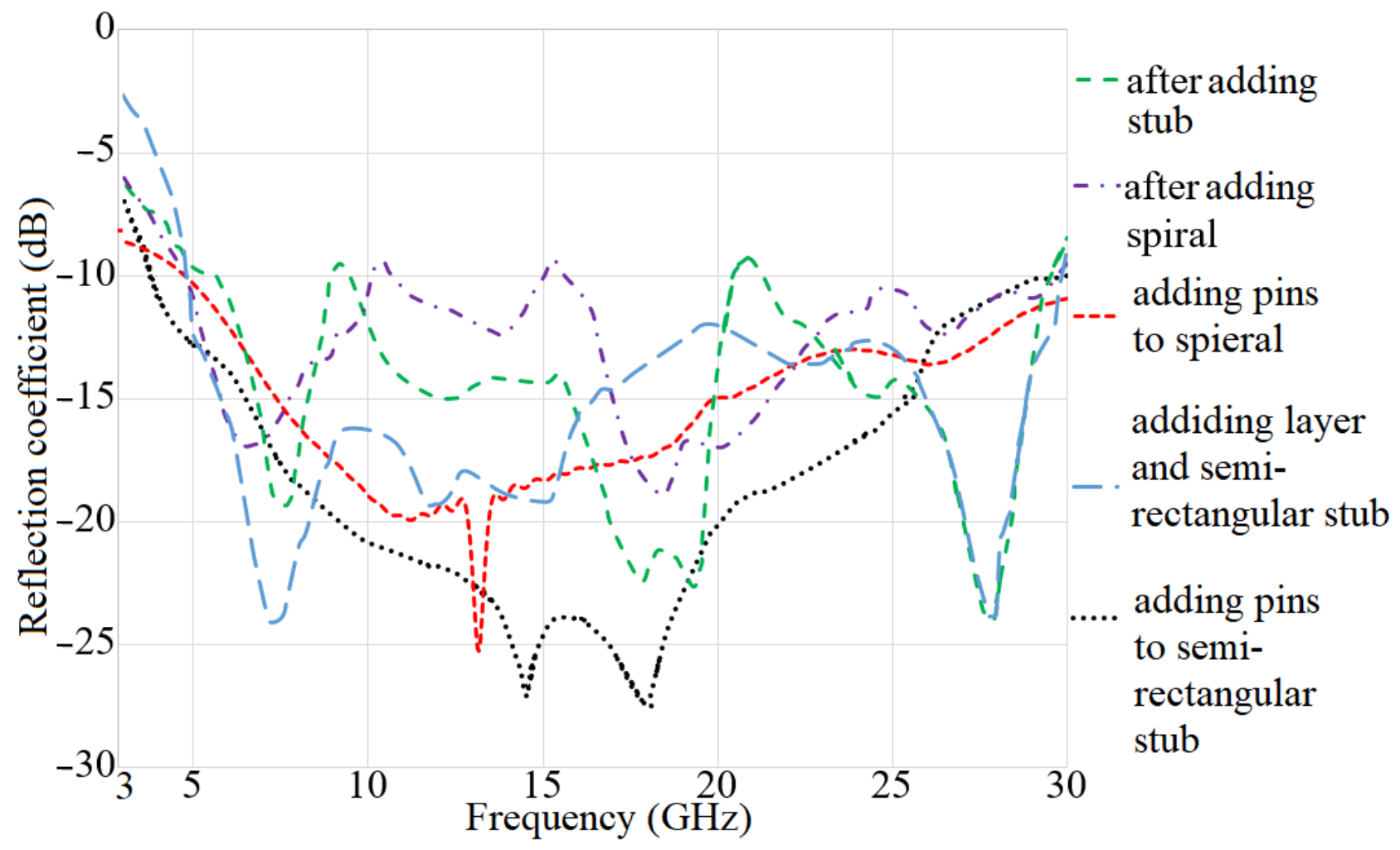

Figure 10. The simulated reflection coefficient results for the proposed single MIMO antenna at each stage of loading.

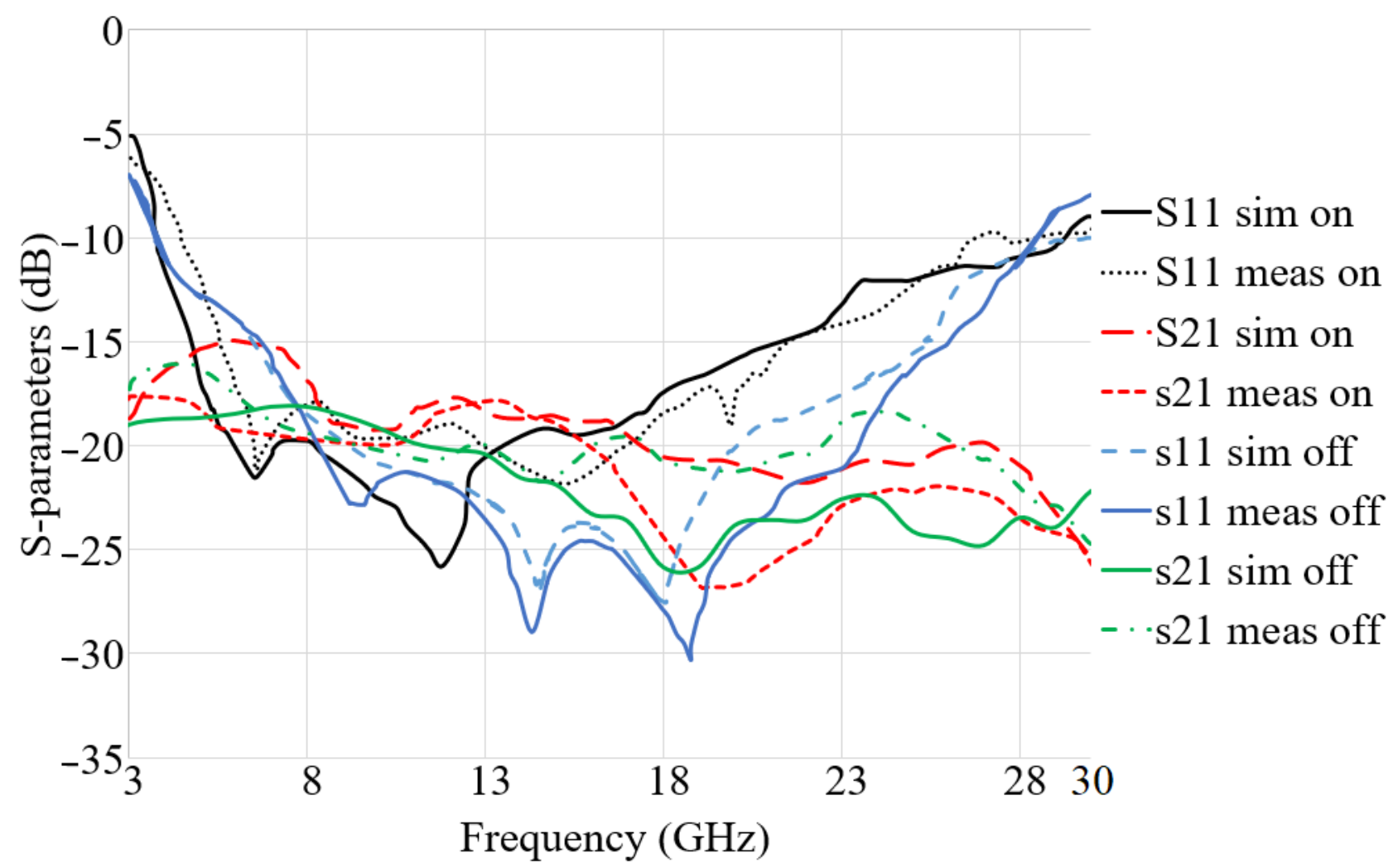

Figure 11. The S-parameters results for the proposed single MIMO antenna, on-body (on the breast phantom), and off-body (free space) for the simulation (sim) and measurements (meas) with all loading. 

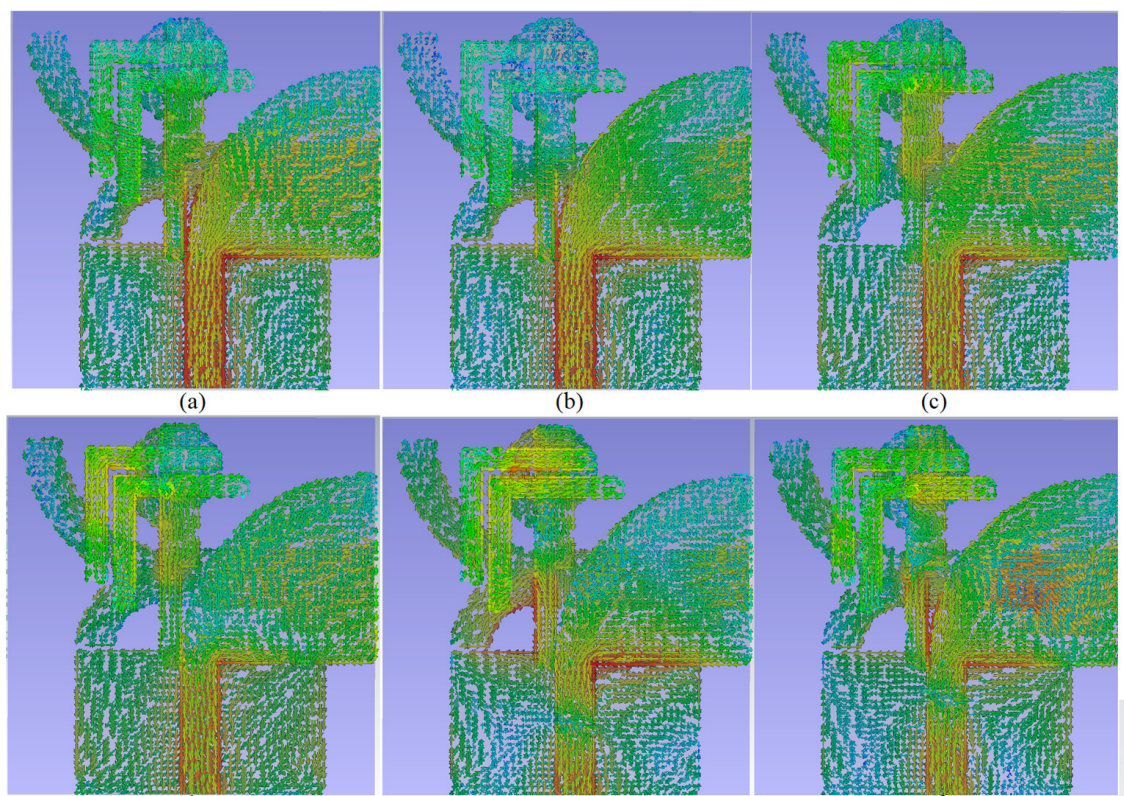

d)
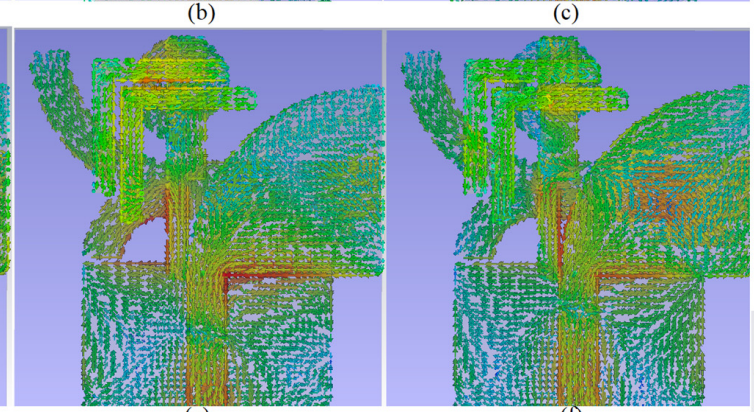

(f)

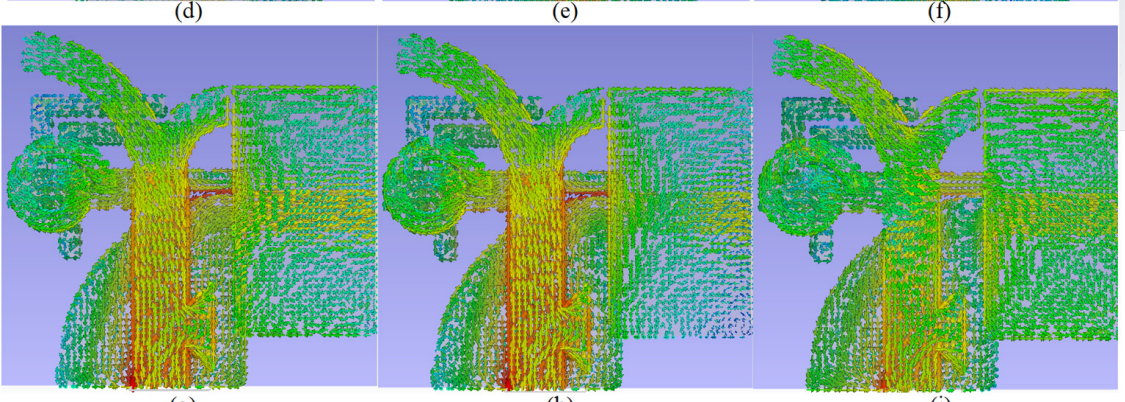

(i)

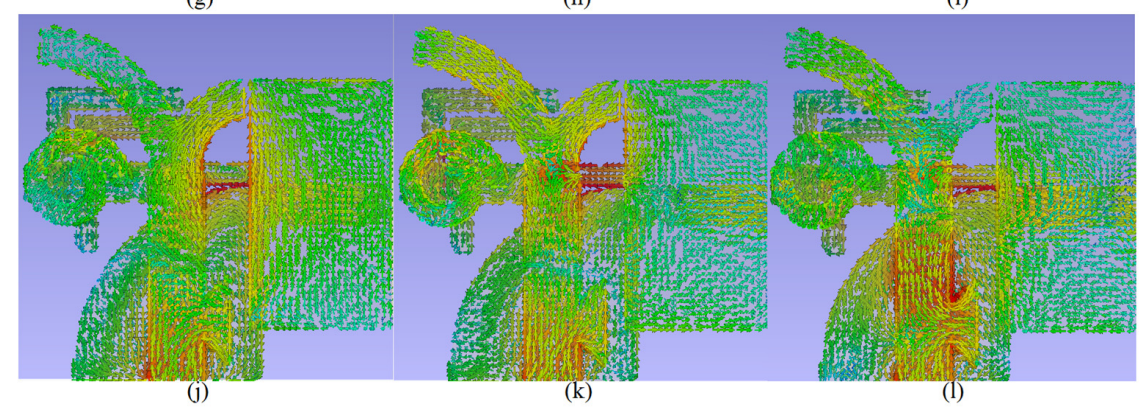

(j)

(k)

(1)

Figure 12. The SCD results for the MIMO antenna after loading (port 1: (a-f), port 2: (g-1) at $6.2 \mathrm{GHz}$, $10.5 \mathrm{GHz}, 12.5 \mathrm{GHz}, 15 \mathrm{GHz}, 20 \mathrm{GHz}$, and $25 \mathrm{GHz}$, respectively).

The two proposed two-port MIMO antennas were integrated with three more single elements to cover more of the area of the breast. The four arrays of two-port MIMO performance in terms of the impedance BW was varied dramatically from the single twoport MIMO. Additionally, the reflection coefficient results for both the simulation and the measurements of the antenna show good agreement. The radiation pattern of the antenna was measured after integration of four single two-port MIMO antennas (eight ports in overall).

Figures 14 and 15 show the measurement setup, simulated, and measured co-polarisation radiation pattern of the eight-port MIMO antenna, respectively. In order to measure the radiation pattern of the antenna on body (breast), the antenna should be located on the breast towards the tangential plane. It is positioned based on the radiation pattern of the antenna itself in air. Moreover, it should be placed in the plane to have the scanning of the breast since the tumour in located at the centre. However, it can be located towards the $\mathrm{Y}$ and $\mathrm{ZX}$ planes for further investigations and adding another eight-port antenna in other planes. 


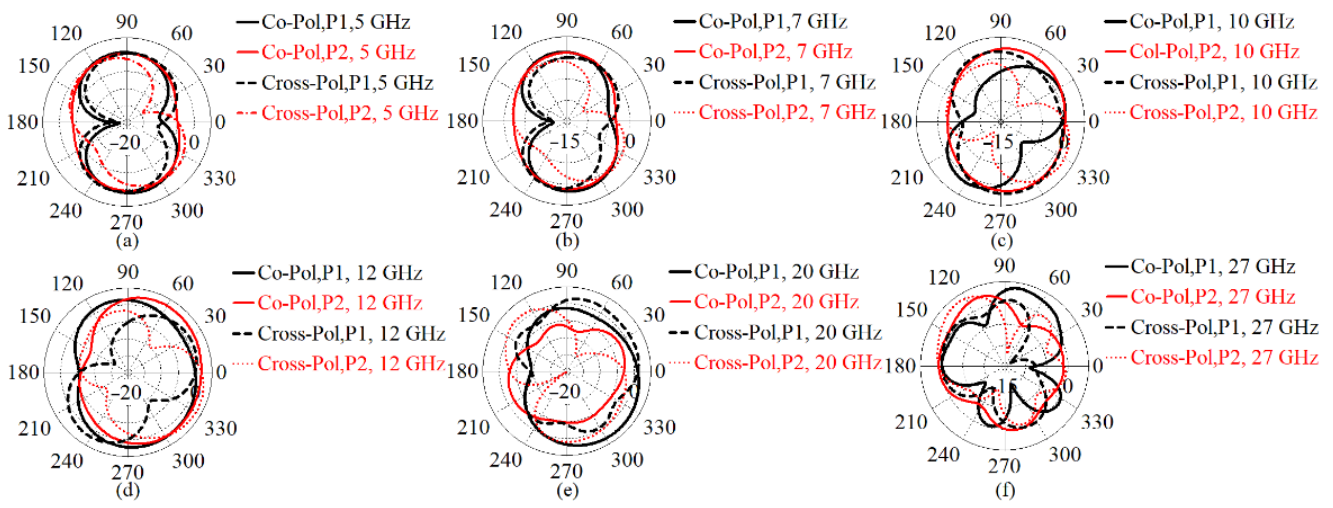

Figure 13. The simulated two-dimensional co-polarisation and cross-polarisation radiation patterns of the proposed on-body antenna in the $x z$ plane $((\mathbf{a}): 3.8 \mathrm{GHz},(\mathbf{b}): 6.2 \mathrm{GHz},(\mathbf{c}): 10.5 \mathrm{GHz}$, (d): $12.5 \mathrm{GHz},(\mathbf{e}): 15 \mathrm{GHz},(\mathbf{f}): 25 \mathrm{GHz})$.

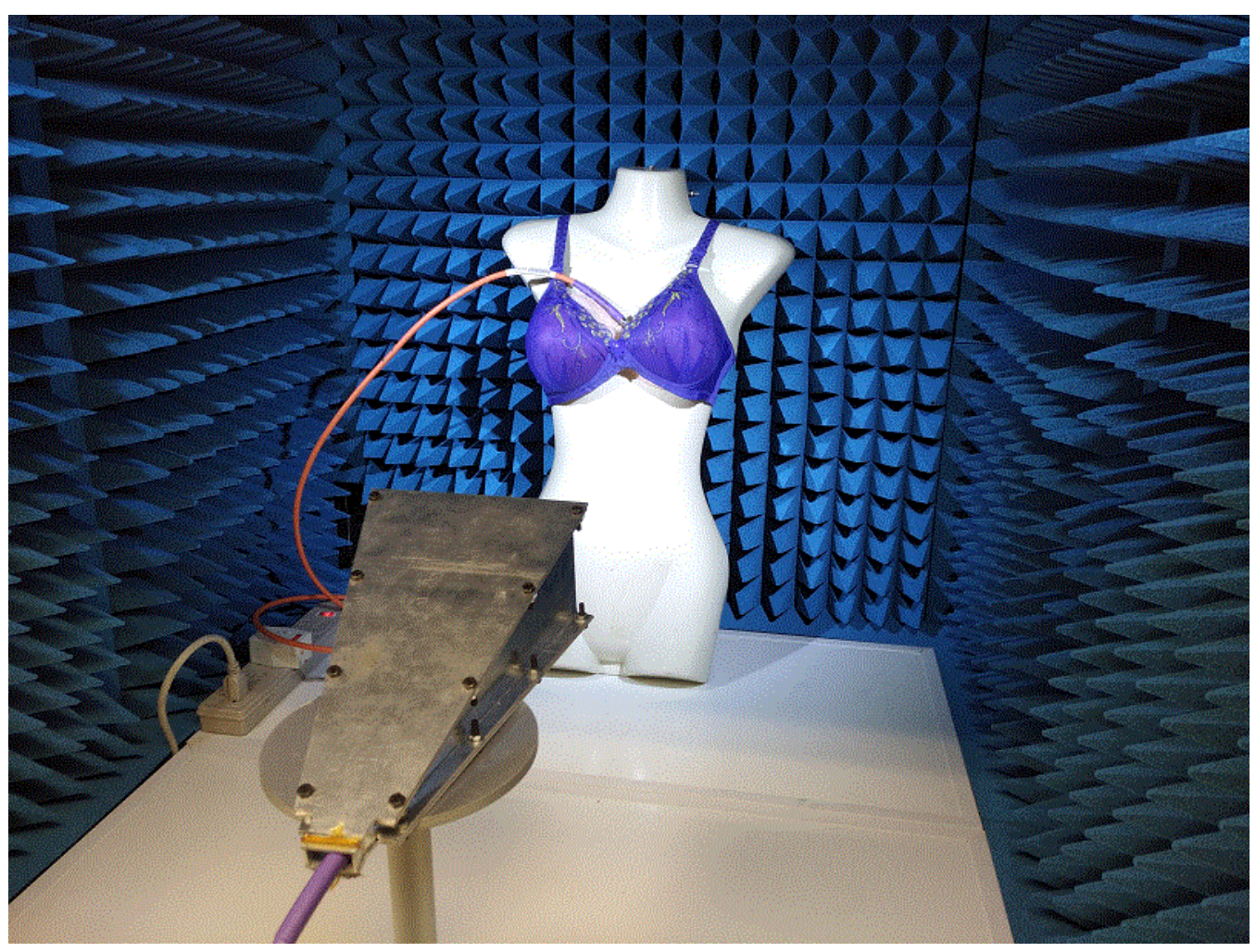

Figure 14. Measurement setup for the radiation pattern of the four array elements of the MIMO antenna (the white box made of foam).

Figure 16 and Table 3 show the simulated and measured gain and radiation efficiency for both on-body (on-body: on the breast) and free space conditions. The optimum value of the gain and the radiation efficiency, respectively, were $5.57 \mathrm{dBi}$ and 96 percent. Furthermore, the entire working BW had a radiation efficiency of more than 81 percent. The antenna's suitability for image reconstruction of tumours could be determined after the antenna's radiation characteristics were examined and tested for on- and off-body conditions. The efficiency is slightly reduced with increases in frequency. This is because of the attenuation of the wave at a higher frequency, especially in breast medium. It should be mentioned that the achieved gain of $6.53 \mathrm{dBi}$, is the maximum gain at high frequency $(27 \mathrm{GHz})$. Moreover, the results shown in Table 3 are results for the four cells of the proposed MIMO. Moreover, in that measurement, the antenna is not directly touching 
the breast sample with high dielectric constant. The phantom layer and a layer of rubber are between them, so it cannot affect the antenna radiation dramatically.

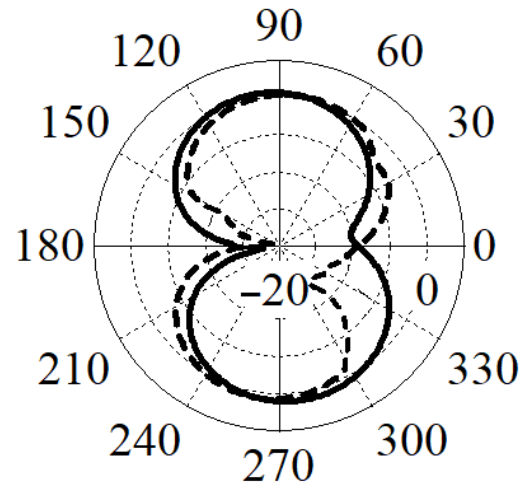

(a)

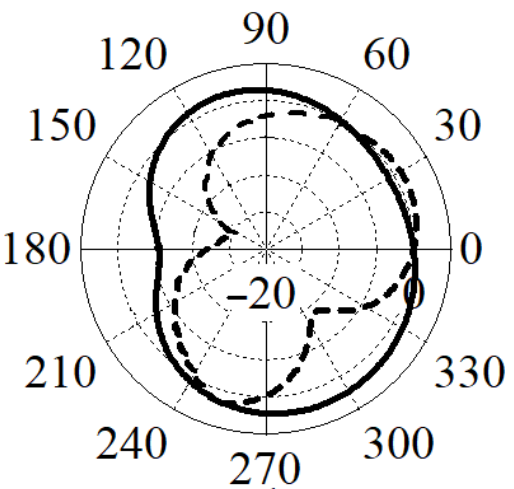

(d)

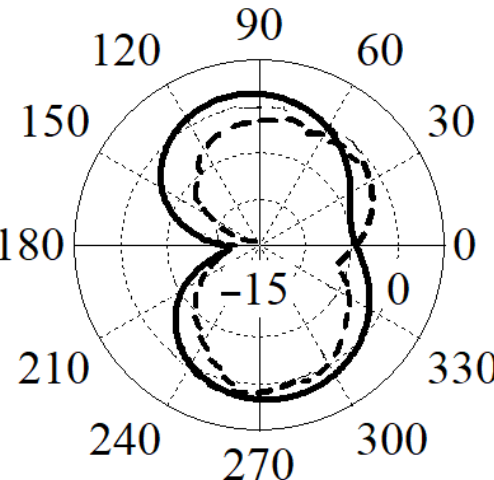

(b)

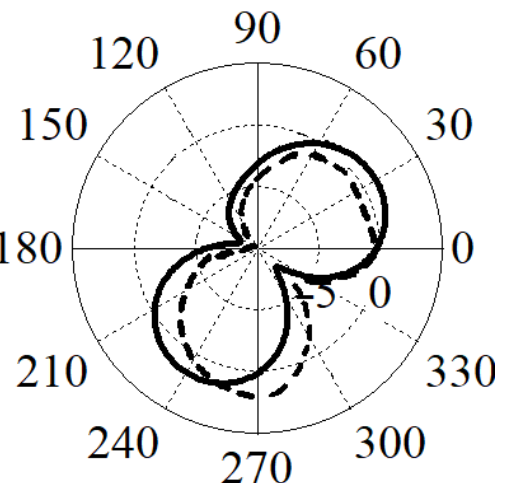

(c)

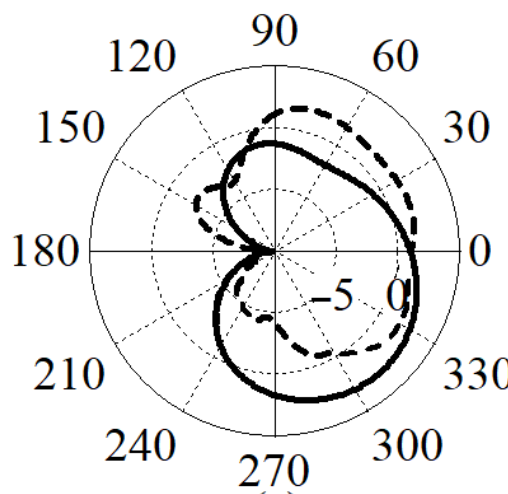

(e)

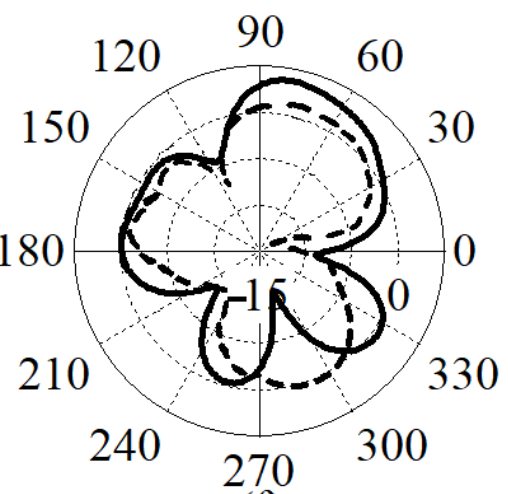

(f)

Figure 15. The co-polarisation radiation pattern of the antenna at (a) $4.8 \mathrm{GHz},(\mathbf{b}) 7 \mathrm{GHz}$, (c) $10 \mathrm{GHz},(\mathbf{d}) 15 \mathrm{GHz},(\mathbf{e}) 20 \mathrm{GHz}$, (f) $27 \mathrm{GHz}$ (solid line: simulated, dashed line: measured).

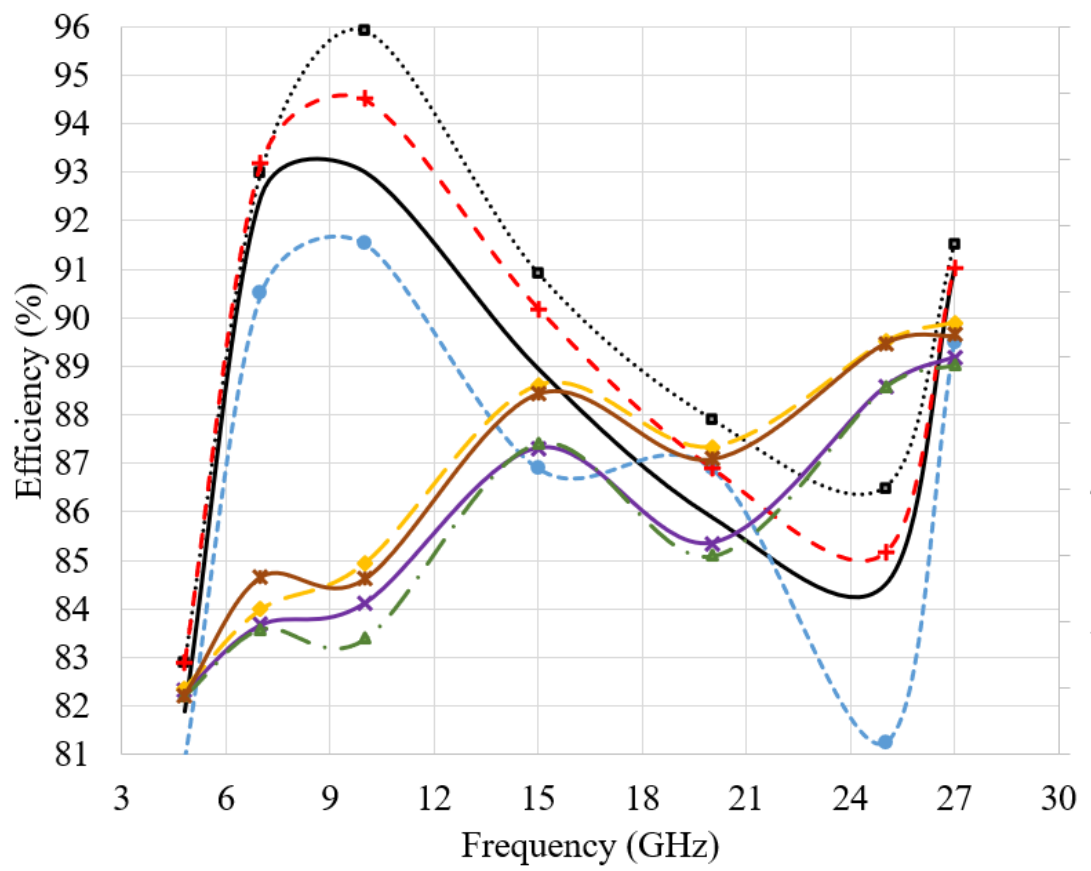

$$
\begin{aligned}
& 11 \text {-Efficiency } \\
& 10 \text { (\%). Sim. On } \\
& \text {..... Efficiency } \\
& \text { (\%).Sim.off } \\
& \text {-๑-Efficiency } \\
& 7 \text {. (\%).Meas.on }
\end{aligned}
$$

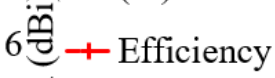

$$
\begin{aligned}
& 5 \text {. } \quad \text { (\%).Meas.off } \\
& 4 * \text { Gain } \\
& \text { (dBi).Sim. On } \\
& \rightarrow \text { Gain } \\
& \text { (dBi).Sim.off } \\
& \rightarrow \text { Gain } \\
& \text { (dBi).Meas.on } \\
& \text {-Gain } \\
& \text { (dBi).Meas.off }
\end{aligned}
$$

Figure 16. Simulated and measured gain and efficiency for both on-body (breast) and off-body (free space) conditions: measurement (Meas) and simulation (Sim). 
Table 3. The gain ( $\mathrm{dBi}$ ) and efficiency (\%) for the simulation (sim) and measurements (meas) (on: on breast and off: free space) for the proposed antenna.

\begin{tabular}{ccccccccc}
\hline $\begin{array}{c}\text { Parameters } \\
f_{\boldsymbol{r}} \mathbf{( G H z )}\end{array}$ & $\begin{array}{c}\text { Eff (\%) } \\
\text { Sim. On }\end{array}$ & $\begin{array}{c}\text { Gain (dBi) } \\
\text { Sim. On }\end{array}$ & $\begin{array}{c}\text { Eff (\%) } \\
\text { Sim. off }\end{array}$ & $\begin{array}{c}\text { Gain (dBi) } \\
\text { Sim. off }\end{array}$ & $\begin{array}{c}\text { Eff (\%) } \\
\text { Meas. on }\end{array}$ & $\begin{array}{c}\text { Gain (dBi) } \\
\text { Meas. on }\end{array}$ & $\begin{array}{c}\text { Eff }(\%) \\
\text { Meas. off }\end{array}$ & $\begin{array}{c}\text { Gain }(\mathbf{d B i}) \\
\text { Meas. off }\end{array}$ \\
\hline 4.8 & 81.90 & 0.57 & 82.95 & 0.91 & 80.70 & 0.49 & 82.90 & 0.90 \\
7 & 92.50 & 0.96 & 93.00 & 1.69 & 90.00 & 0.90 & 92.00 & 1.68 \\
10 & 93.00 & 1.68 & 95.90 & 2.73 & 91.53 & 1.75 & 94.19 & 2.65 \\
15 & 88.95 & 4.66 & 90.80 & 5.58 & 86.91 & 4.70 & 90.77 & 5.45 \\
20 & 85.27 & 3.27 & 87.50 & 4.65 & 84.36 & 3.02 & 86.58 & 4.46 \\
25 & 81.56 & 5.56 & 84.00 & 6.24 & 80.47 & 5.55 & 84.25 & 6.01 \\
27 & 89.00 & 6 & 91.25 & 6.53 & 89.00 & 5.89 & 91.16 & 6.33 \\
\hline
\end{tabular}

For both the 1 and $10 \mathrm{~g}$ standards, it must be less than $2 \mathrm{~W} / \mathrm{Kg}$, according to industry and government standards. Table 4 shows that the antenna provides suitable SARs for both standards at various frequencies. Figure 17 depicts the SAR distribution on the body (breast) for the single two-port MIMO antenna, in addition to Table 4. A layer of skin, breast fat, muscle, and bone were used to measure the SAR on the body; measurements were collected with the antenna located near the breast ( $4 \mathrm{~mm}$ distant from the breast).

Table 4. Specific absorption rate (SAR) values at various bands and specifications for single MIMO.

\begin{tabular}{ccccc}
\hline $\mathrm{SAR} / f_{r}$ & $\mathbf{4 . 8} \mathbf{~ G H z}(\mathbf{1} \mathbf{g}, \mathbf{1 0} \mathbf{~ g})$ & $\mathbf{1 0 ~ G H z}(\mathbf{1} \mathbf{g}, \mathbf{1 0} \mathbf{g})$ & $\mathbf{1 5 ~ G H z}(\mathbf{1} \mathbf{g}, \mathbf{1 0} \mathbf{g})$ & $\mathbf{2 7} \mathbf{~ G H z}(\mathbf{1} \mathbf{~ g}, \mathbf{1 0} \mathbf{g})$ \\
\hline Values $(\mathrm{W} / \mathrm{Kg})$ & $0.115,0.671$ & $0.71,1.93$ & $1.79,1.41$ & $2.01,0.984$ \\
\hline
\end{tabular}

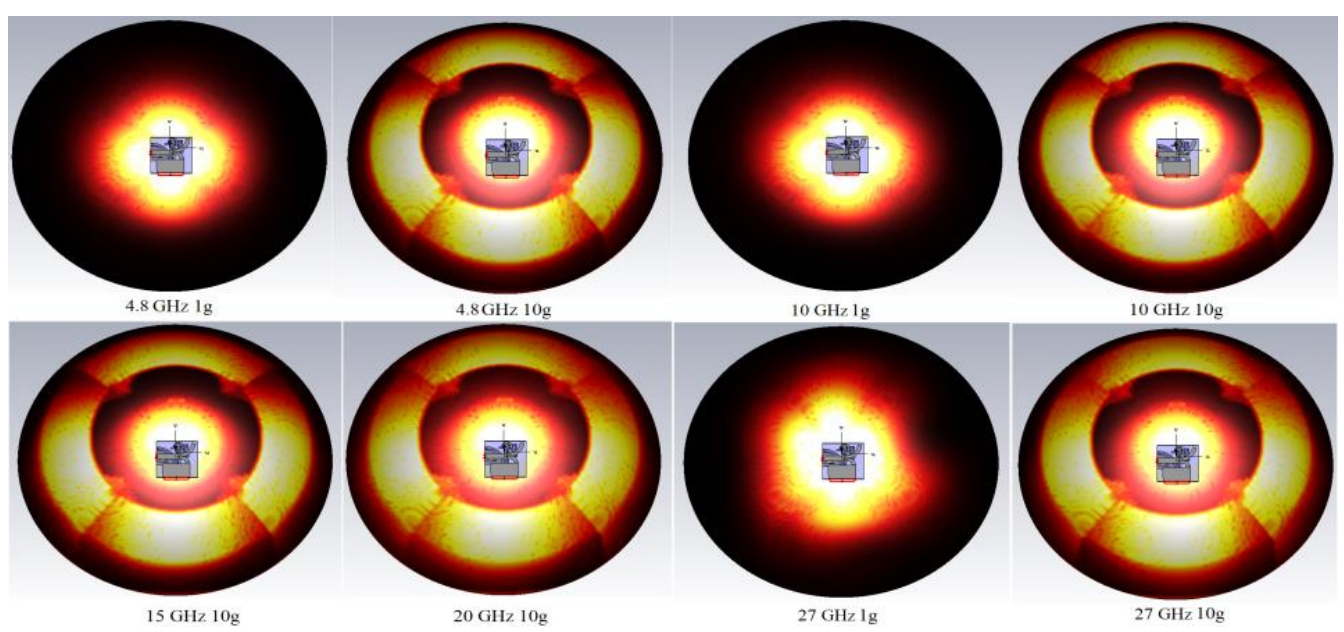

Figure 17. Variation of specific absorption rate (SAR) for a single MIMO on the breast at various bands and specifications $(1 \mathrm{~g}, 10 \mathrm{~g})$.

\subsection{Near-Field Investigation of the Proposed Antenna for Image Reconstruction}

In both the time and frequency domains, the proposed wearable UWB antenna was investigated. The antennas with narrow BW are normally defined and propagated in the frequency domain, and their radiation characteristics are assumed to be persistent over a small percentage of the working bandwidth. The characteristics of the antenna were examined in the time domain under the intensity of a continuous wave [3,15], since UWB systems are often thought to be impulse-based technologies. The research in the frequency domain was based on a two-dimensional vector with orthogonally polarization elements. The transient response of an antenna, on the other hand, is primarily affected by time, as well as the angles of departure and polarization. Figure 18 depicts the simulation setup, which included sending and receiving a UWB pulse between every two UWB antennas [15]. 


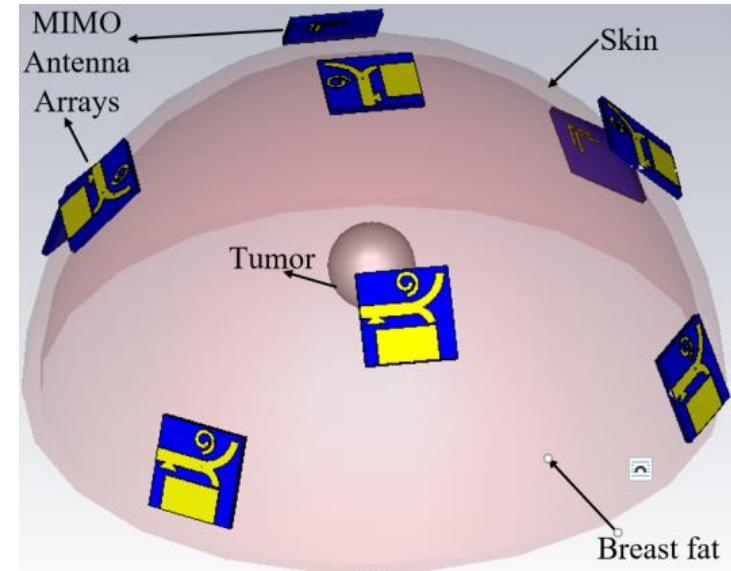

(a)

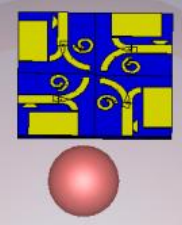

(b)

Figure 18. Simulated structure of the antenna array elements in on-body conditions: (a) single MIMO array, (b) four MIMO arrays.

Until beginning the image construction of a breast tumour, several critical factors that influence these processes should be examined and evaluated. Figure 18a depicts the simulation setup of nine array elements of the single MIMO two-port antenna around a $100 \mathrm{~mm}$-diameter breast phantom, while Figure 18b depicts the eight-port MIMO antenna (four single MIMO antenna). First, analyse the signals obtained from the various arrays. The signal analysis was used to recreate the image of the tumour using the obtained signals and the time delay.

Figure 19 depicts a pulse that is generally transmitted to the medium by the antennas to demonstrate how a signal sends and receives in microwave imaging and the scanning medium. $\mathrm{h}(\mathrm{t})$ denotes the time domain impulse response (a Gaussian signal with a maximum amplitude of 1 is used as the antenna's input), and $|\mathrm{h}+(\mathrm{t})|$ denotes the envelope of the impulse response, which localizes the energy distribution versus time. It is also used as a reliable predictor of an antenna's dispersion). The $p(\theta, \psi)$ and $(\tau)$ represent the envelope peak value, which displays the antenna's time domain transient response envelope's strongest peak, and the envelope width, which displays the widening of the radiating impulse and is calculated as the size of the analytical envelope at half maximum. To achieve a high channel capacity and good resolution in communications, the $\tau$ should not surpass more than a few hundred picoseconds (high resolution is vital in microwave imaging to obtain a nicer image of the breast and the tumour within). Additionally, a UWB antenna's ringing is an undesirable characteristic generated by resonances generated by energy storage or numerous reflections. Furthermore, it is described as the number it takes for the envelope to decline from its maximum level to a lower limit, which should be negligible, only about a few envelopes' width. The ringing is not needed in the first place, and it can be avoided by using absorber substances (which can be placed all over the antenna or system). Aside from the absorbing substance, ringing can be eliminated in the imaging section with the right algorithm and time window.

Figure 20 shows the received signals from the various array elements (A1-A9, port 2-port 18) in both on- and off-body conditions. The signals were transmitted by Port one (P1) in Array one (A1), and they were received by the other arrays. When this signal was applied to the breast model, the form of the signal did not change, but the amplitude of the signal changed and moved. Furthermore, when a tumour was present, the signal amplitude was lower. The received signals and transmission coefficients were shown only for four elements in Figures 20 and 21, because it meant to show better understanding and differences among each of the array element results. 


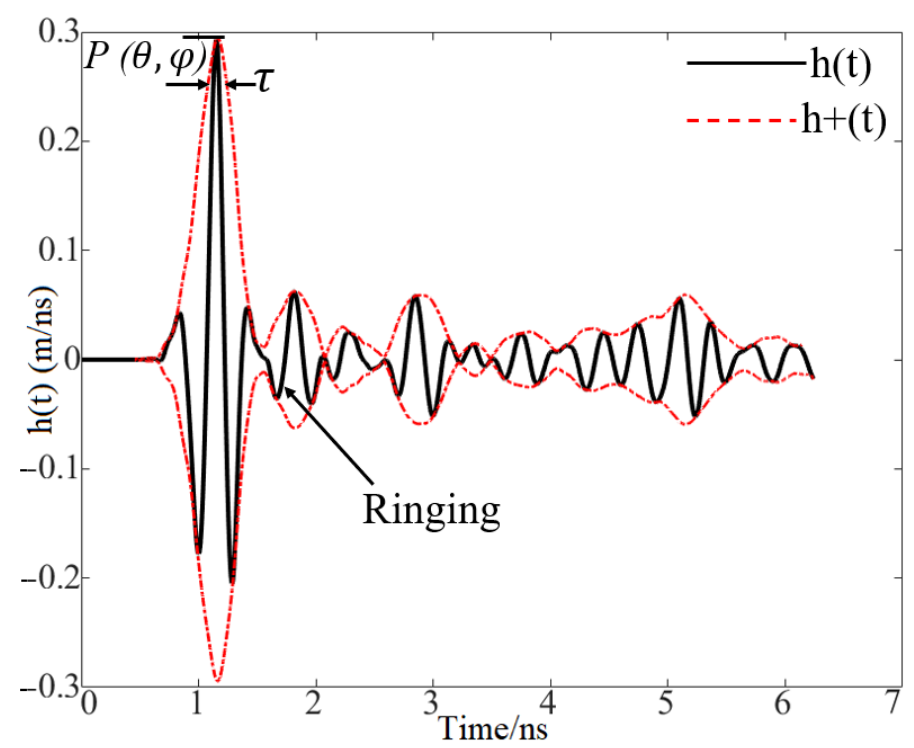

Figure 19. The transmitted pulse from the antenna array elements.

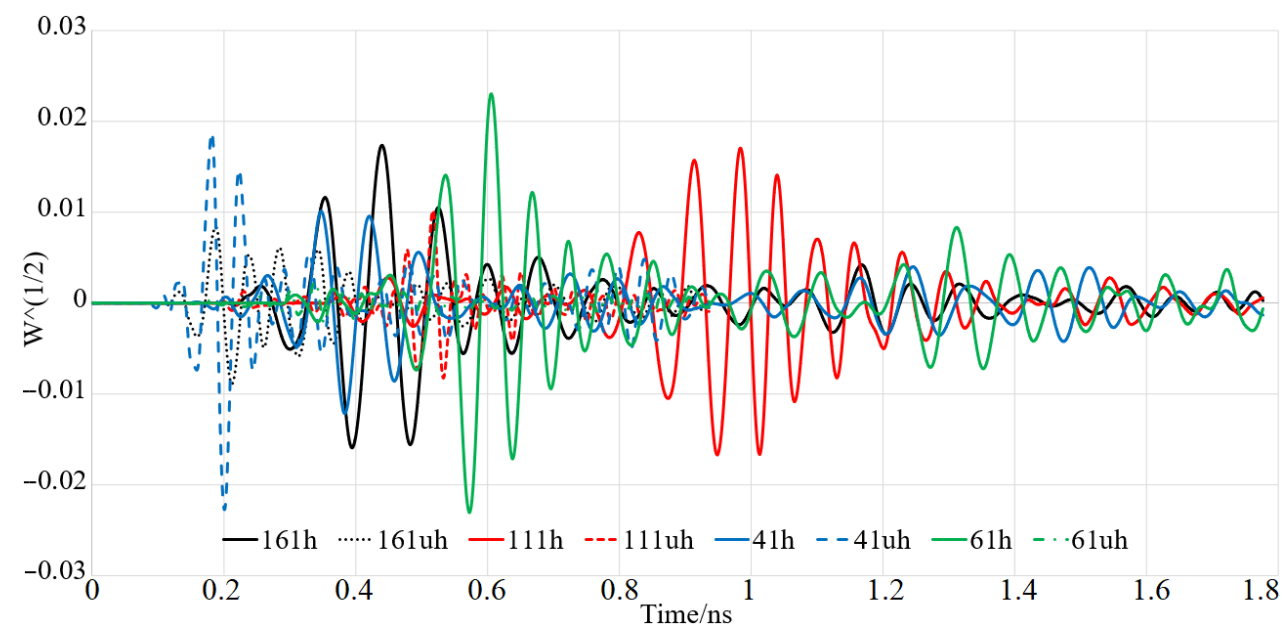

Figure 20. Received signals with (uh) and without (h) tumour.

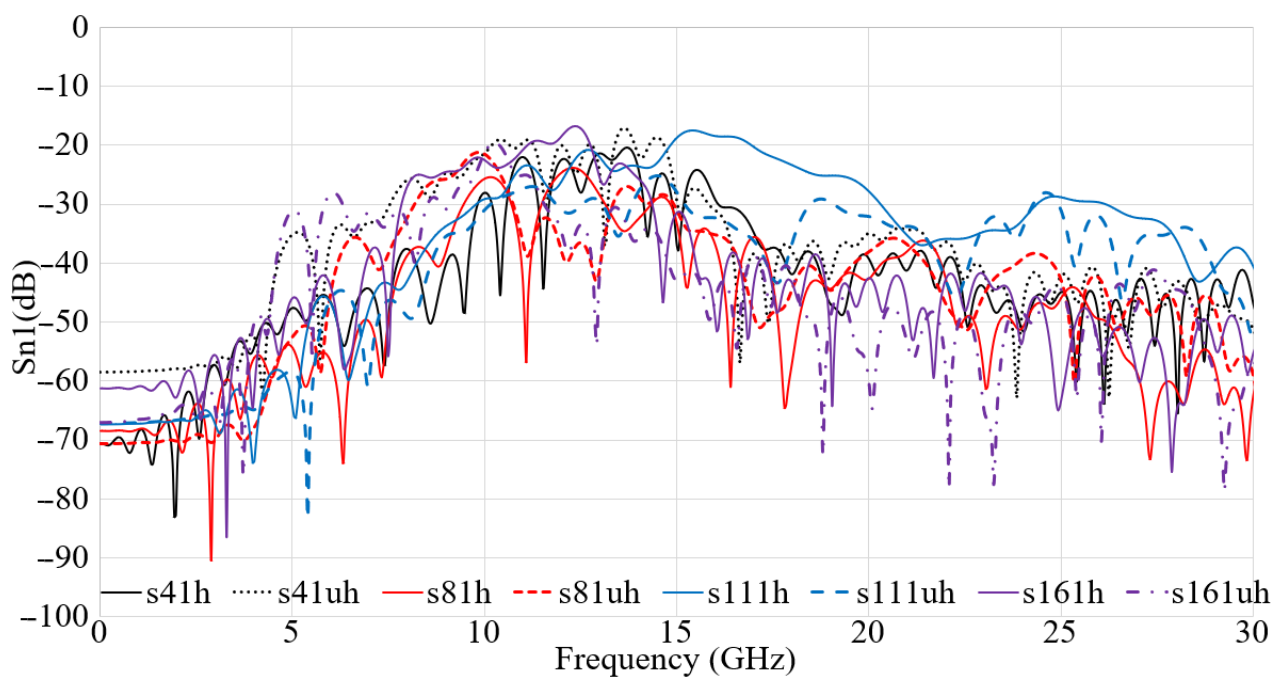

Figure 21. Setup of antenna array components in a simulated on-body environment (with (uh) and without (h) a tumour). 
The transmission coefficients of the nine arrays of single MIMO positioned around the breast model, as shown in Figure 18a, are shown in Figure 21. In both cases, the transmission coefficient level was less than $-18 \mathrm{~dB}$ for both arrays, as shown in Figure 21 (with and without a tumour). In microwave imaging, the fidelity factor is a critical parameter to consider. It depicts the similarities in received signals from various arrays at various angles. It also shows how much distortion is present in the signal as it travels from the transmitter to the receiver arrays. For on-body settings, Figure 22 depicts the high fidelity of received signals from various arrays (with and without the presence of a tumour).

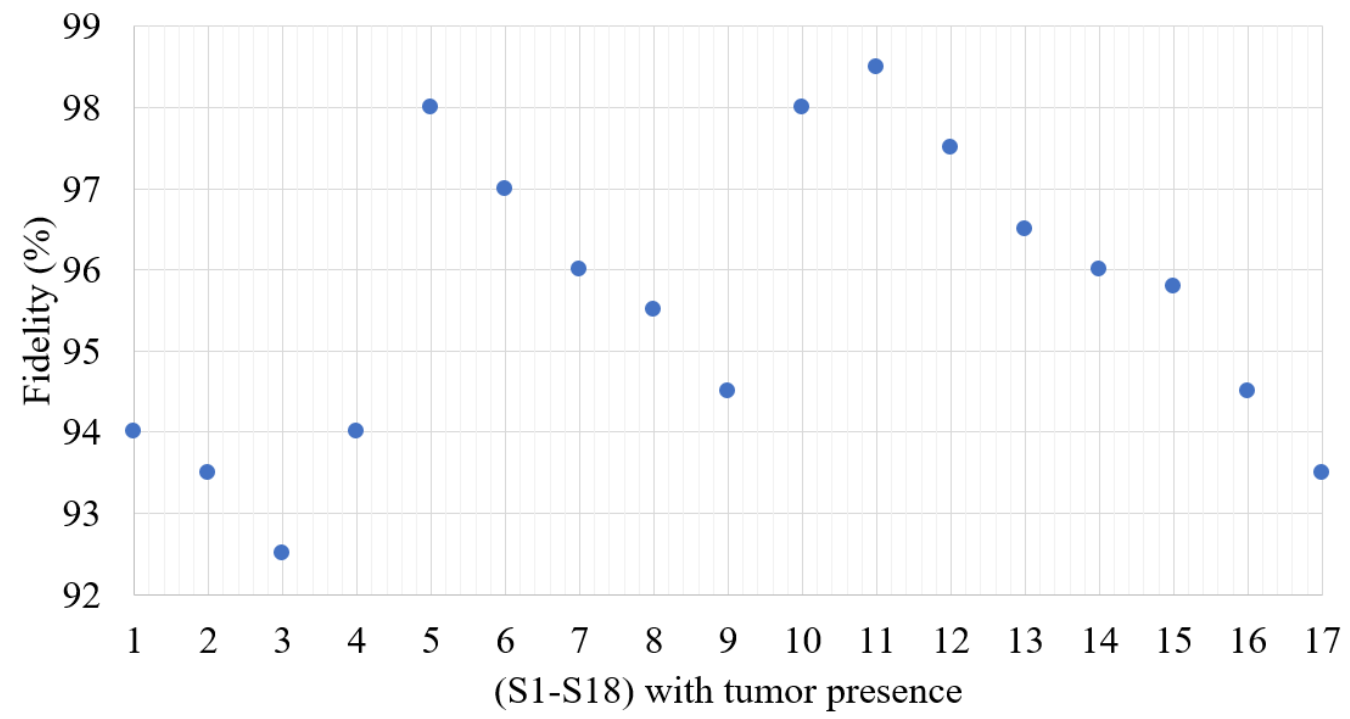

Figure 22. Simulated fidelity factor for on-body conditions when a tumour exists.

The energy flux density (EFD) is determined in the $X$ and $Z$ axes, starting from the feeding point of antenna to $50 \mathrm{~mm}$ away from its aperture. It is also to calculate the beamwidth. For the $X$ plane, these statistics are given in Figure 23 for both antennas. Broadside radiation behaviour is clearly seen. Whenever the frequency is raised, there is a minor enhance in back radiation. After the radiation behaviour is examined in the frequency domain, it is discovered that the grating lobes surrounding the primary lobe of the radiation pattern grow in size as the frequency increases (Figure 23).

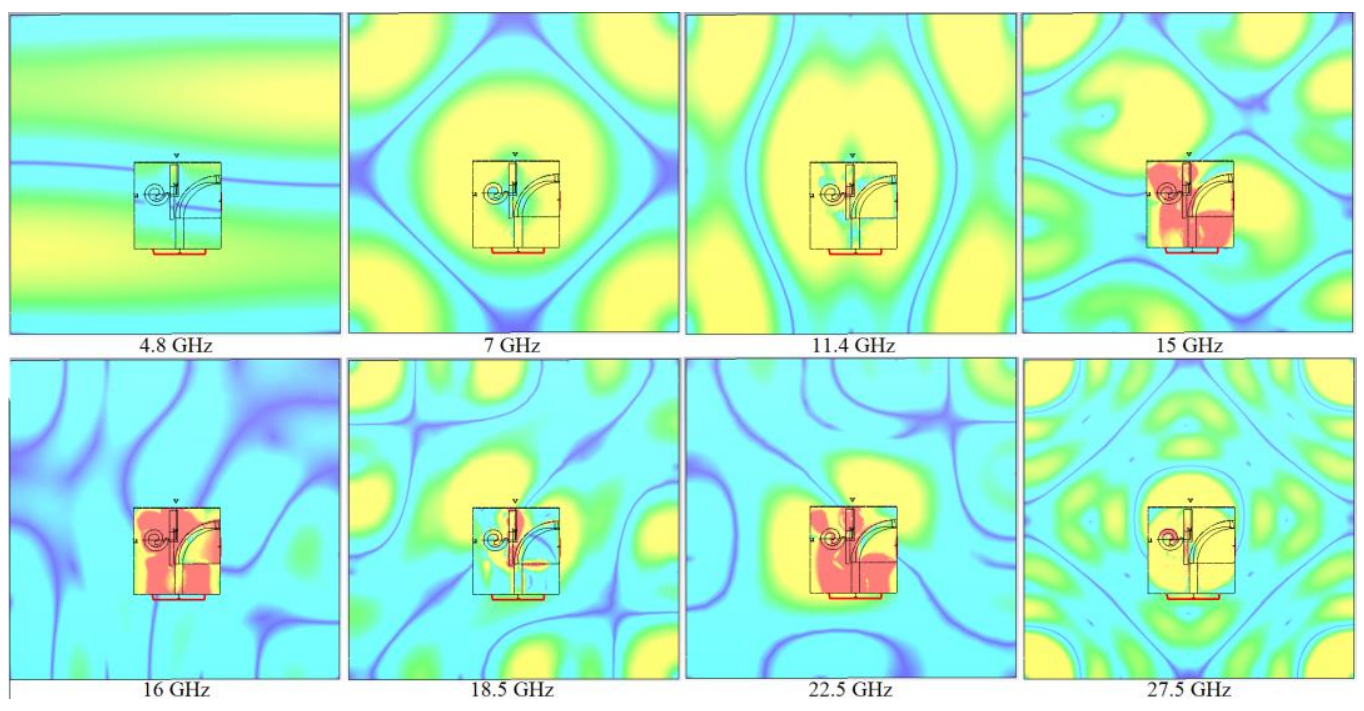

Figure 23. Simulated electric fields at the working resonances and poles. 
Electromagnetic (EM) waves are also utilized to convey data from one location to another via a wireless channel or a guided architecture. The time-averaged Poynting vector (average power density) is a cross product of $\mathrm{E}$ and $\mathrm{H}^{*}$. It is applied to characterize the power density related with an EM wave. It should be mentioned that the real part of the excitation pulse reflects the reactive (stored) power density (PD) related with EM fields, whereas the imaginary component reflects the propagated PD. The real portion is in charge of transferring power from an antenna to the others. Figure 24 depicts the real component of the Poynting vector for the other nine arrays while one antenna (Tx) propagates. Furthermore, as shown in Figure 24, significant penetrating of EM waves into the breast improves the link's power efficiency and the capability of locating the tumour in the breast.

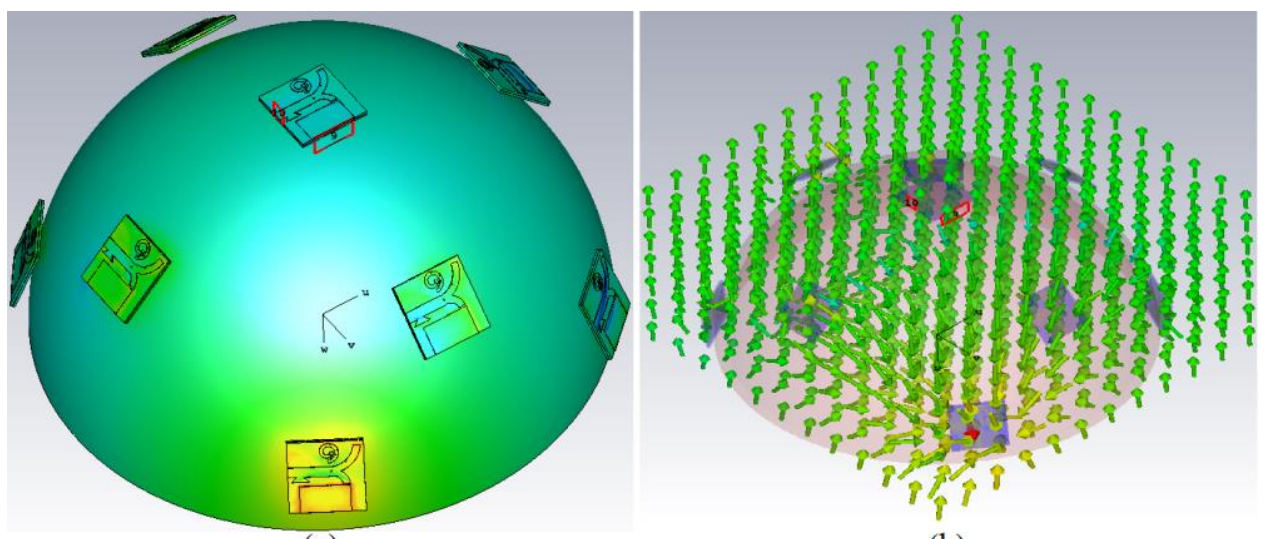

(a)

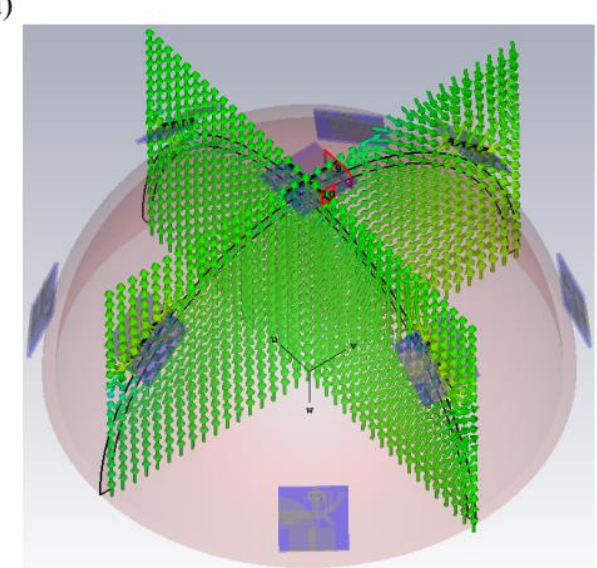

(c) (b)

Figure 24. The Poynting vector (the real part) ((a): when port one is active, $(\mathbf{b})$ : in simulation environment, (c): the $\mathrm{E}$ and $\mathrm{H}$ planes).

The energy transmitted by the antenna determines the half energy beamwidth (HEBW) and half energy beam (HEB). By aggregating time sampling of the simultaneous Poynting vector over the simulation period, the energy in and around the antenna construction is estimated (EFD). In the near-field microwave imaging, the HEBW is specified on a perpendicular plane to the primary radiation beam at a certain range from aperture of the antenna. The HEBW denotes the region on the specified plane where the energy is larger than $50 \%$ of the original level. The HEBW is calculated in both the $x$ and $z$ planes. The HEB tries to depict the radiation beam in the near-field in a more generic way. In the near-field, the HEB description is useful because it simulates the radiation behaviour as a function of the antenna model by incorporating the beam source knowledge. This enables comparing radiation patterns between antennas easier, as well as predicting the radiation covering of an object positioned near the antenna (Figure 25). 


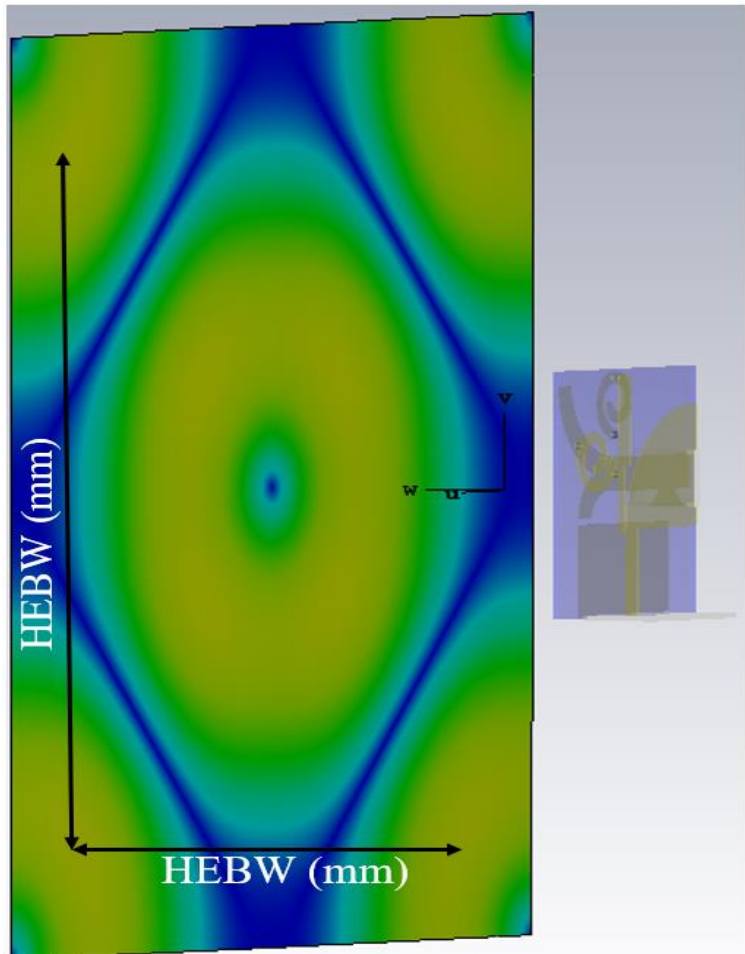

Figure 25. Half Energy Beam at centre frequency.

\subsection{Image Reconstruction of a Tumour for Various Conditions}

When the proposed antenna's characteristics in both on- and off-body environments (with and without a tumour) were assessed, the antenna's suitability for image reconstruction of breast tumours was tested under a variety of conditions: with a central tumour (small and large tumours), an off-centre tumour, two tumours, and three tumours. The reconstructed image is shown in Figure 26 using the RTR algorithm described in [64]. In all five conditions, the spherical tumours were perfectly detectable. In these photographs, there were just a few tiny, unnoticeable clutters.

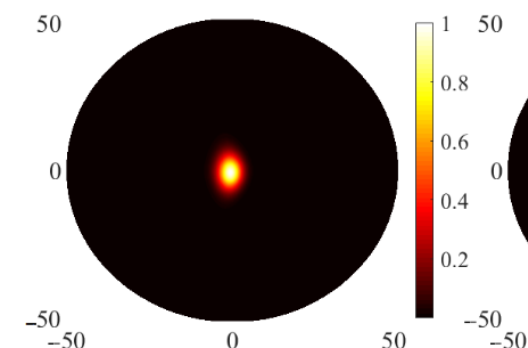

(a)

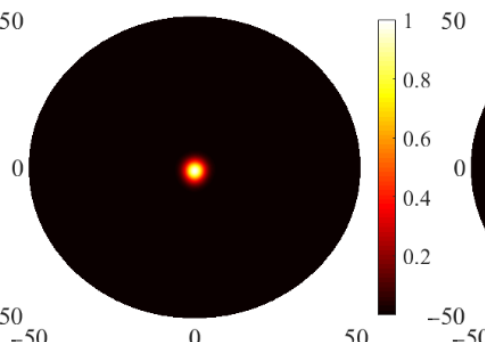

(b)

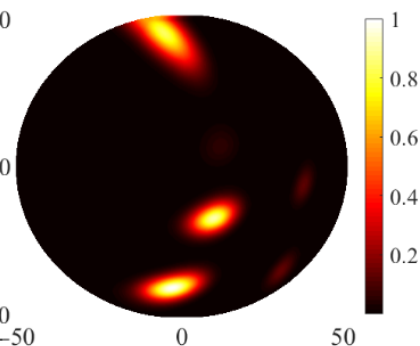

(c)

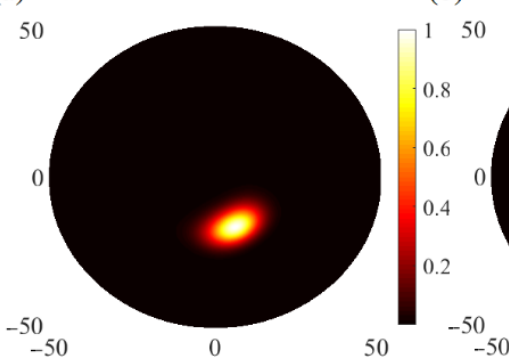

(d)

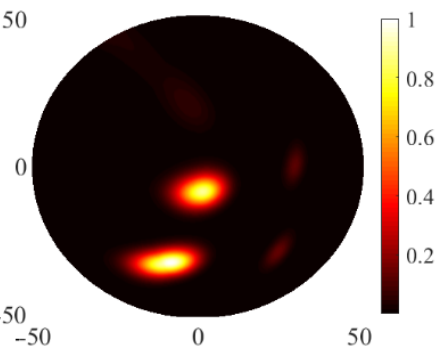

(e)

Figure 26. Images were reconstructed using four arrays of obtained signals and a reliable time reversal algorithm [64]: (a) central tumour of diameter $10 \mathrm{~mm}$, (b) central tumour of diameter $6 \mathrm{~mm}$, (c) three tumours, (d) off-centre tumour, and (e) two tumours. 
It can be assumed that it is a viable candidate for use as a wearable system for early detection of breast cancer when the reconstructed images using the proposed antennas could detect the tumour for all the conditions.

Tables 5 and 6 compare the proposed research with some previous related studies. The proposed antenna has a wider BW, higher gain and radiation quality, and lower SAR values. These outcomes were achieved for the proposed antenna, which has relatively small dimensions compared with recent works. Only one of these reports used a complete ground [65]. Since obtaining a wide BW by using a full ground is difficult, several UWB, wideband, and broadband antennas use shortened GNDs to increase BW.

Table 5. The proposed antenna's performance in comparison with similar studies $\left(f_{L}\right.$ is lowest operating frequency).

\begin{tabular}{|c|c|c|c|c|c|c|}
\hline Ref No. & Dimensions (mm) & $f_{L}(\mathrm{GHz})$ & BW (GHz) & Max Efficiency (\%) & Max Gain (dBi) & SAR (W/Kg) \\
\hline$[66]$ & $0.31 \lambda_{0} \times 0.31 \lambda_{0}$ & 3.1 & 8.2 & 60.00 & 4.00 & - \\
\hline [67] & $1.27 \lambda_{0} \times 1.27 \lambda_{0}$ & 2.075 & 8.3 & - & 7.76 & 0.164 \\
\hline [68] & $0.24 \lambda_{0} \times 0.24 \lambda_{0}$ & 2.96 & 0.55 & - & 5.47 & 1.68 \\
\hline [69] & $0.46 \lambda_{0} \times 0.46 \lambda_{0}$ & 3.1 & 7.9 & - & 3.50 & - \\
\hline [70] & $0.65 \lambda_{0} \times 0.65 \lambda_{0}$ & 4.55 & 8.85 & - & 6.00 & 0.067 \\
\hline [71] & $0.22 \lambda_{0} \times 0.32 \lambda_{0}$ & 2 & 11.7 & - & 4.30 & - \\
\hline [72] & $0.16 \lambda_{0} \times 0.33 \lambda_{0}$ & 2.5 & 8.5 & - & - & - \\
\hline [73] & $0.15 \lambda_{0} \times 0.24 \lambda_{0}$ & 2.82 & 11.63 & 91.70 & 6.86 & - \\
\hline [74] & $0.24 \lambda_{0} \times 0.30 \lambda_{0}$ & 3 & 9.6 & - & 5.20 & - \\
\hline [75] & $0.30 \lambda_{0} \times 0.21 \lambda_{0}$ & 1.83 & 11.99 & - & 4.21 & 0.335 \\
\hline [76] & $22 \times 22$ & 2 & 10 & $<85$ & 11.2 & $\mathrm{~N} / \mathrm{A}$ \\
\hline Proposed & $0.38 \lambda_{0} \times 0.38 \lambda_{0}$ & 4.8 & 25.2 & 96.00 & 5.72 & 0.115 \\
\hline
\end{tabular}

Table 6. The proposed antenna's features in comparison with similar studies.

\begin{tabular}{|c|c|c|c|c|}
\hline Ref No. & Application & Substrate $\left(\varepsilon_{r}, h(\mathrm{~mm})\right)$ & Feeding & Radiation \\
\hline$[66]$ & Wearables & Felt $(1.2,0.7)$ & TL and partial GND & Nearly omni \\
\hline [67] & ISM Wearables & Jeans $(1.7,1)$ & TL and partial GND, FSS & omni \\
\hline [68] & Wearable UWB, mobile health & Jeans $(1.7,1)$ & TL and partial GND & Omni and Quasi-omni \\
\hline [69] & UWB communication & FR4 $(4.3,0.87)$ & TL and a slotted GND & Nearly omni \\
\hline [70] & Wearables, WBAN & Felt $(1.4,1)$ & TL and partial GND & Broad side \\
\hline [71] & UWB communication & FR4 $(4.4,1.6)$ & TL and stepped GND & Nearly bidirectional \\
\hline [72] & MIMO packaging application & FR4 $(4.3,1.6)$ & TL and stepped GND & Nearly omni \\
\hline [73] & MIMO and UWB communication & FR4 $(4.4,1.6)$ & TL and defected partial GND & Omni and bidirectional \\
\hline [74] & UWB applications & FR4 $(4.3,0.8)$ & TL and partial GND & Omni \\
\hline [75] & Wearables & Jeans $(2,1.59)$ & Partially etched GND & Unidirectional \\
\hline Proposed & $\begin{array}{l}\text { Wearable, ISM, MIMO and } \\
\text { UWB communication }\end{array}$ & $\begin{array}{c}\text { Felt }(1.8,09), \\
\text { Denim }(1.2,0.5)\end{array}$ & TL and partial GND & Directional \\
\hline
\end{tabular}

\section{Conclusions}

During the creation of a wearable UWB antenna, SAR values can be a massive obstacle. Shortened GNDs, on the other hand, are often applied in wearable antenna architectures to achieve the optimal ultra-wide bandwidth, but this raises the SAR value, which is unacceptable for wearable antennas. As a result, a UWB antenna with a full GND was planned, simulated, and calculated in order to attain a large BW with consistent radiation properties while keeping the SAR value within a reasonable range, depending on applicable specifications. The recommended antenna was created using two layers of felt and denim substrates, 
with thicknesses of $0.5 \mathrm{~mm}$ and $0.9 \mathrm{~mm}$, respectively, and $\varepsilon_{r}=1.2$ and 1.8 , respectively, as well as ShieldIt ${ }^{\mathrm{TM}}$, a conductive textile, with a thickness of $0.17 \mathrm{~mm}$. This gave a combined volume of $11 \times 11 \times 1.4 \mathrm{~mm}^{3}$ for a single two-port MIMO and $24 \times 24 \times 1.4 \mathrm{~mm}^{3}$ for four elements fabricated from single two-port MIMO antennas. The recommended antenna had a working BW of 4.8-30 GHz, a highest directive gain of $5.72 \mathrm{dBi}$, and a 96 percent radiation efficiency. Following the investigation of the antenna's performance in free space, its radiation properties were investigated in a new medium, the breast, to detect a tumour in a variety of circumstances, including a central tumour with and without skin, as well as multiple tumours (two and three) inside the breast. The created images demonstrated that the antenna works well in breast tissue and is a good choice for use in a wearable WBAN device for breast cancer tracking and imaging. Moreover, its tiny dimensions, the antenna's feeding, and grounding make it simple to integrate with electronic components such as wearable micro electromechanical systems (MEMs).

Author Contributions: S.N.M. and T.S., designed, simulated, performed the experiments, wrote the required programs, and wrote a complete draft of the paper. T.S. and A.J., supervised, evaluated, and edited the paper. A.J.I. and A.C.S., supervised the project and secured the funding for the project. S.S., Q.H.A. and M.A.I., edited the paper and helped in data collection and evaluation. All authors have read and agreed to the published version of the manuscript.

Funding: This research was supported by Universiti Putra Malaysia through Putra Grant (GP/2018/ 9606000). We also want to thank the Department of Electrical and Electronic Engineering of Universiti Putra Malaysia for funding this research work.

Conflicts of Interest: The authors declare no conflict of interest.

\section{References}

1. Alhawari, A.R.H.; Almawgani1, A.H.M.; Hindi, A.T.; Alghamdi, H.; Saeidi, T. Metamaterial-based wearable flexible elliptical UWB antenna for WBAN and breast imaging applications. AIP Adv. 2021, 11, 015128. [CrossRef]

2. Caldeira, J.M.; Rodrigues, J.J.; Lorenz, P. Toward ubiquitous mobility solutions for body sensor networks on healthcare. IEEE Commun. Mag. 2012, 50, 108-115. [CrossRef]

3. Badhan, K.; Singh, J. Analysis of Different Performance Parameters of Bodywearable Antenna- A Review. Adv. Wirel. Mob. Commun. 2017, 10, 735-745.

4. Kirtania, S.G.; Elger, A.W.; Hasan, M.R.; Wisniewska, A.; Sekhar, K.; Karacolak, T.; Sekhar, P.K. Flexible Antennas: A Review. Micromachines 2020, 11, 847. [CrossRef]

5. Al-Sehemi, A.G.; Al-Ghamdi, A.A.; Dishovsky, N.T.; Atanasov, N.T.; Atanasova, G.L. Flexible and small wearable antenna for wireless body area network applications. J. Electromagn. Waves Appl. JEWA 2017, 31, 1063-1082. [CrossRef]

6. Chen, S.J.; Ranasinghe, D.C.; Fumeaux, C. A robust snap-on button solution for reconfigurable wearable textile antennas. IEEE Trans. Antennas Propag. 2018, 66, 4541-4551. [CrossRef]

7. Yan, S.; Vandenbosch, G.A. Radiation pattern-reconfigurable wearable antenna based on metamaterial structure. IEEE Antennas Wirel. Propag. Lett. 2016, 15, 1715-1718. [CrossRef]

8. Azeez, H.I.; Yang, H.-C.; Chen, W.-S. Wearable triband E-shaped dipole antenna with low SAR for IoT applications. Electronic 2019, 8, 665. [CrossRef]

9. Al-Ghamdi, A.A.; Al-Hartomy, O.A.; Al-Solamy, F.R.; Dishovsky, N.T.; Atanasov, N.T.; Atanasova, G.L. Enhancing antenna performance and SAR reduction by a conductive composite loaded with carbon-silica hybrid filler. AEU Int. J. Electron. Commun. 2017, 72, 184-191. [CrossRef]

10. Wang, C.; Yeo, J.C.; Chu, H.; Lim, C.T.; Guo, Y.X. Design of a reconfigurable patch antenna using the movement of liquid metal. IEEE Antennas Wirel. Propag. Lett. 2018, 17, 974-977. [CrossRef]

11. Tong, X.; Liu, C.; Liu, X.; Guo, H.; Yang, X. Dual-band on-/off-body reconfigurable antenna for wireless body area network (WBAN) applications. Microw. Opt. Technol. Lett. 2018, 60, 945-951. [CrossRef]

12. Jang, T.; Zhang, C.; Youn, H.; Zhou, J.; Guo, L.J. Semitransparent and Flexible Mechanically Reconfigurable Electrically Small Antennas Based on Tortuous Metallic Micromesh. IEEE Trans. Antennas Propag. 2017, 65, 1. [CrossRef]

13. Simorangkir, R.B.; Yang, Y.; Esselle, K.P.; Zeb, B.A. A method to realize robust flexible electronically tunable antennas using polymer-embedded conductive fabric. IEEE Trans. Antennas Propag. 2017, 66, 50-58. [CrossRef]

14. Cai, Y.; Qian, Z.; Cao, W.; Zhang, Y. Research on the half complementary split-ring resonator and its application for designing miniaturized patch antenna. Microw. Opt. Technol. Lett. 2015, 57, 2601-2604. [CrossRef]

15. Saeidi, T.; Ismail, I.; Alhawari, A.R.; Wen, W.P. Near-field and far-field investigation of miniaturized UWB antenna for imaging of wood. AIP Adv. 2019, 9, 035232. [CrossRef] 
16. Sharony, J. Introduction to Wireless MIMO-Theory and Applications. CEWITA IEEE LI. 2006. Available online: https / / ieee.li/ pdf/viewgr-aphs/Introd (accessed on 15 November 2006).

17. Shoaib, N.; Shoaib, S.; Khattak, R.Y.; Shoaib, I.; Chen, X.; Perwaiz, A. MIMO antennas for smart 5G devices. IEEE Access 2018, 6, 77014-77021. [CrossRef]

18. Uthansakul, P.; Assanuk, D.; Uthansakul, M. An optimal design of multiple antenna positions on mobile devices based on mutual coupling analysis. Int. J. Antennas Propag. 2011, 2011, 791697. [CrossRef]

19. Chen, X.; Zhang, S.; Li, Q. A review of mutual coupling in MIMO systems. IEEE Access 2018, 6, 24706-24719. [CrossRef]

20. Ayman, A. Althuwayb, Low-Interacted Multiple Antenna Systems Based on Metasurface-Inspired Isolation Approach for MIMO Applications. Arab. J. Sci. Eng. 2021. [CrossRef]

21. Shirkolaei, M.M. Wideband linear microstrip array antenna with high efficiency and low side lobe level. Int. J. RF Microw. Comput. Aided Eng. 2020, e22412. [CrossRef]

22. Maleki, A.; Oskouei, H.D.; Shirkolaei, M.M. Miniaturized microstrip patch antenna with high inter-port isolation for full duplex communication system. Int. J. RF Microw. Comput. Eng. 2021, 31, e22760. [CrossRef]

23. Alibakhshikenari, M.; Babaeian, F.; Virdee, B.S.; Aissa, S.; Azpilicueta, L.; See, C.H.; Althuwayb, A.A.; Huynen, I.; Abd-Alhameed, R.A.; Falcone, F.; et al. A Comprehensive Survey on "Various Decoupling Mechanisms with Focus on Metamaterial and Metasurface Principles Applicable to SAR and MIMO Antenna Systems". IEEE Access 2020, 8, 192965-193004. [CrossRef]

24. Guo, J.; Liu, F.; Jing, G.; Zhao, L.; Yin, Y.; Huang, G. Mutual coupling reduction of multiple antenna systems. Front. Inform. Technol. Electron. Eng. 2020, 21, 366-376. [CrossRef]

25. Lin, Y.; Chen, W.; Chen, C.; Liao, C.; Chuang, N.; Chen, H. High-gain MIMO dipole antennas with mechanical steerable main beam for 5G small cell. IEEE Antennas Wirel. Propag. Lett. 2019, 18, 1317-1321. [CrossRef]

26. Wang, Z.; Du, Y.A. Wideband printed dual-antenna with three neutralization lines for mobile terminals. IEEE Trans. Antennas Propag. 2014, 62, 1495-1500. [CrossRef]

27. Su, F.S.; Lee, S.W.; Chang, C.T. Printed MIMO-antenna system using neutralization-line technique for wireless USB-dongle applications. IEEE Trans. Antennas Propag. 2012, 60, 456-463. [CrossRef]

28. Zhao, K.L.; Wu, L.A. Decoupling technique for four-element symmetric arrays with reactively loaded dummy elements. IEEE Trans. Antennas Propag. 2014, 62, 4416-4421. [CrossRef]

29. Yeung, Y.E.; Wang, L.K. Mode-based beamforming arrays for miniaturized platforms. IEEE Trans. Microw. Theory Tech. 2009, 57, 45-52. [CrossRef]

30. Wang, T.F.; Li, K.; Eibert, L. Comparison of compact monopole antenna arrays with eigenmode excitation and multiport conjugate matching. IEEE Trans. Antennas Propag. 2013, 61, 4054-4062. [CrossRef]

31. Andersen, J.; Rasmussen, H. Decoupling and descattering networks for antennas. IEEE Trans. Antennas Propag. 1976, 24, 841-846. [CrossRef]

32. Ostadrahimi, M.; Noghanian, S.; Shafai, L.; Zakaria, A.; Kaye, C.; LoVetri, J. Investigating double-layer Vivaldi antenna for fixed array field measurement. Int. J. Ultra Wideband Commun. Syst. 2010, 1, 282-290. [CrossRef]

33. Ostadrahimi, M.; Mojabi, P.; Noghanian, S.; Shafai, L.; Pistorius, S.; LoVetri, J. A novel microwave tomography system based on the scattering probe technique. IEEE Trans. Instrum. Measur. 2012, 61, 379-390. [CrossRef]

34. Wang, Y.; Yu, Z. A novel symmetric double-slot structure for antipodal Vivaldi antenna to lower cross-polarization level. IEEE Trans. Antennas Propag. 2017, 65, 5599-5604. [CrossRef]

35. Moosazadeh, M.; Kharkovsky, S. A compact high-gain and front-to-back ratio elliptically tapered antipodal Vivaldi antenna with trapezoid-shaped dielectric lens. IEEE Antennas Wirel. Propag. Lett. 2016, 15, 552-555. [CrossRef]

36. Chen, L.; Lei, Z.; Yang, R.; Fan, J.; Shi, X. A broadband artificial material for gain enhancement of antipodal tapered slot antenna. IEEE Trans. Antennas Propag. 2015, 63, 395-400. [CrossRef]

37. Zhang, J.; Zhang, X.; Xiao, S. Antipodal Vivaldi antenna to detect uhf signals that leaked out of the joint of a transformer. Int. J. Antennas Propag. 2017, 9627649. [CrossRef]

38. Garg, R.; Bhartia, P.; Bahl, I.; Ittipiboon, A. Microstrip Antenna Design Handbook; Artech House INC: Norwood, MA, USA, 2001.

39. Saeidi, T.; Ismail, I.; Noghanian, S.; Alhawari, A.R.H.; Abbasi, Q.H.; Imran, M.A.; Zeain, M.Y.; Ali, S.M. High Gain Triple-Band Metamaterial-Based Antipodal Vivaldi MIMO Antenna for 5G Communications. Micromachines 2021, 12, 250. [CrossRef]

40. Wang, L.; Huang, B. Design of Ultra-WidebandMIMO Antenna for Breast Tumor Detection. Int. J. Antennas Propag. 2012, 2012, 180158. [CrossRef]

41. Chen, Y.; Gunawan, E.; Low, K.S.; Wang, S.C.; Kim, Y.; Soh, C.B. Pulse design for time reversal method as applied to ultrawideband microwave breast cancer detection: A twodimensional analysis. IEEE Trans. Antennas Propag. 2007, 55, 194-204. [CrossRef]

42. Davis, S.K.; Van Veen, B.D.; Hagness, S.C.; Kelcz, F. Breast tumor characterization based on ultrawideband microwave backscatter. IEEE Trans. Biomed. Eng. 2008, 55, 237-246. [CrossRef]

43. Hilger, I.; Geyer, C.; Rimkus, G.; Helbig, M.; Sachs, J.; Schwarz, U.; Hein, M.A.; Kaiser, W.A. Could we use UWB sensing for breast cancer detection? In Proceedings of the Fourth European Conference on Antennas and Propagation, Barcelona, Spain, 12-16 April 2010; IEEE: Piscataway, NJ, USA, 2010; pp. 1-4.

44. Daniel, O.T.; Yuanjin, Z.; Zhiping, L. Design and experimental investigation of UWB microwave imaging via MIMO beamforming. In Proceedings of the IEEE International Conference on Ultra-Wideband (ICUWB '10), Nanjing, China, 20-23 September 2010; IEEE: Piscataway, NJ, USA, 2010; pp. 851-854. 
45. Davis, S.K.; Tandradinata, H.; Hagness, S.C.; Van Veen, B.D. Ultrawideband microwave breast cancer detection: A detectiontheoretic approach using the generalized likelihood ratio test. IEEE Trans. Biomed. Eng. 2005, 52, 1237-1250. [CrossRef]

46. Bliss, D.W.; Forsythe, K.W. MIMO Radar medical imaging: Self-interference mitigation for breast tumor detection. In Proceedings of the 40th Asilomar Conference on Signals, Systems, and Computers (ACSSC '06), Pacific Grove, CA, USA, 29 October-1 November 2006; IEEE: Piscataway, NJ, USA, 2006; pp. 1558-1562.

47. Muhajr, A.B.; Mahdi, J.; Khadhim, M.A. Design of Ultra-Wideband MIMO Antenna for Breast Tumor Detection. In IOP Conference Series: Materials Science and Engineering; IOP Publishing: Bristol, UK, 2020; Volume 881, p. 012111. [CrossRef]

48. Saxena, G.; Jain, P.; Awasthi, Y.K. High Diversity Gain MIMO-Antenna for UWB Application with WLAN Notch Band Characteristic Including Human Interface Devices. Wirel. Pers. Commun. 2019, 112, 105-121. [CrossRef]

49. Hu, Z.; Zeng, Z.; Wang, K.; Feng, W.; Zhang, J.; Lu, Q.; Kang, X. Design and Analysis of a UWB MIMO Radar System with Miniaturized Vivaldi Antenna forThrough-Wall Imaging. Remote Sens. 2019, 11, 1867. [CrossRef]

50. Yang, B.; Zhuge, X.; Yarovoy, A.G.; Ligthart, L.P. UWB MIMO Antenna Array Topology Design Using PSO for Through Dress Near-field Imaging. In Proceedings of the 38th European Microwave Conference, Delft, The Netherlands, 31 October 2006; IEEE: Piscataway, NJ, USA, 2008.

51. Mahmood, S.N.; Ishak, A.J.; Saeidi, T.; Soh, A.C.; Jalal, A.; Imran, M.A.; Abbasi, Q.H. Full Ground Ultra-Wideband Wearable Textile Antenna for Breast Cancer and Wireless Body Area Network Applications. Micromachines 2021, 12, 322. [CrossRef]

52. Alam, M.; Misran, N.; Yatim, B.; Islam, M.T. Development of Electromagnetic Band Gap Structures in the Perspective of Microstrip Antenna Design. Int. J. Antennas Propag. 2013, 2013, 22. [CrossRef]

53. Nassar, I.T.; Weller, T.M. A novel method for improving antipodal Vivaldi antenna performance. IEEE Trans. Antennas Propag. 2015, 63, 3321-3324. [CrossRef]

54. Amiri, M.; Tofigh, F.; Ghafoorzadeh-Yazdi, A.; Abolhasan, M. Exponential antipodal Vivaldi antenna with exponential dielectric lens. IEEE Antennas Wirel. Propag. Lett. 2017, 16, 1792-1795. [CrossRef]

55. Ahadi, M.; Isa, M.B.M.; Saripan, M.I.B.; Hasan, W.Z.W. Square monopole antenna for microwave imaging, design and characterisation. IET Microw. Antennas Propag. 2015, 9, 49-57. [CrossRef]

56. Eichenberger, J.; Yetisir, E.; Ghalichechian, N. High-Gain Antipodal Vivaldi Antenna with Pseudoelement and Notched Tapered Slot Operating at (2.5 to 57) GHz. IEEE Trans. Antennas Propag. 2019, 67, 4357-4366. [CrossRef]

57. Islam, M.M.; Islam, M.T.; Samsuzzaman, M.; Faruque, M.R. Compact metamaterial antenna for UWB applications. Electron. Lett. 2015, 51, 1222-1224. [CrossRef]

58. Li, Y.; Li, W.; Yu, W. A Switchable UWB Slot Antenna using SIS-HSIR and SIS-SIR for Multi-Mode Wireless Communications Applications. ACES J. 2012, 27, 4.

59. Li, Y.; Li, W.; Ye, Q. A Reconfigurable Triple-Notch-Band Antenna Integrated with Defected Microstrip Structure Band-Stop Filter for Ultra-Wideband Cognitive Radio Applications. Int. J. Antennas Propag. 2013, 2013, 472645. [CrossRef]

60. Liu, F.; Guo, J.; Zhao, L.; Huang, G.; Li, Y.; Yin, Y. Ceramic Superstrate-based Decoupling Method for Two Closely Packed Antennas with Cross-Polarization Suppression. IEEE Trans. Antennas Propag. 2020, 69, 1751-1756. [CrossRef]

61. Jiang, J.; Xia, Y.; Li, Y. High Isolated X-Band MIMO Array Using Novel Wheel-Like Metamaterial Decoupling Structure. Aces J. 2019, 34, 12.

62. Luo, S.; Li, Y.; Xia, Y.; Zhang, L. A Low Mutual Coupling Antenna Array with Gain Enhancement Using Metamaterial Loading and Neutralization Line Structure. Aces J. 2019, 34, 3.

63. Li, Y.; Li, W.; Yu, W. A Multi-Band/UWB MIMO/Diversity Antenna with an Enhanced Isolation Using Radial Stub Loaded Resonator. Aces J. 2013, 28, 1.

64. Saeidi, T.; Ismail, I.; Mahmood, S.N.; Alani, S.; Alhawari, A.R. Microwave imaging of voids in oil palm trunk applying UWB antenna and robust time-reversal algorithm. J. Sens. 2020, 2020, 8895737. [CrossRef]

65. Simorangkir, R.B.; Kiourti, A.; Esselle, K.P. UWB wearable antenna with a full ground plane based on PDMS-embedded conductive fabric. IEEE Antennas Wirel. Propag. Lett. 2018, 17, 493-496. [CrossRef]

66. Gharbi, M.; Martinez-Estrada, M.; Fernández-García, R.; Ahyoud, S.; Gil, I. A novel ultra-wide band wearable antenna under different bending conditions for electronic-textile applications. J. Text. Inst. 2021, 112, 437-443. [CrossRef]

67. Sugumaran, B.; Balasubramanian, R.; Palaniswamy, S.K. Reduced specific absorption rate compact flexible monopole antenna system for smart wearable wireless communications. Eng. Sci. Technol. Int. J. 2021, 20, 682-693.

68. Yadav, A.; Singh, V.K.; Bhoi, A.K.; Marques, G.; Garcia-Zapirain, B.; Torre Díez, I. Wireless Body Area Networks: UWB Wearable Textile Antenna for Telemedicine and Mobile Health Systems. Micromachines 2020, 11, 558. [CrossRef] [PubMed]

69. Kumar, S.; Lee, G.H.; Kim, D.H.; Mohyuddin, W.; Choi, H.C.; Kim, K.W. A compact four-port UWB MIMO antenna with connected ground and wide axial ratio bandwidth. Int. J. Microw. Wirel. Technol. 2019, 12, 75-85. [CrossRef]

70. Yalduz, H.; Tabaru, T.E.; Kilic, V.T.; Turkmen, M. Design and analysis of low profile and low SAR full-textile UWB wearable antenna with metamaterial for WBAN applications. Int. J. Electron. Commun. 2020, 126, 153465. [CrossRef]

71. Altaf, A.; Iqbal, A.; Smida, A.; Smida, J.; Althuwayb, A.A.; Hassank Kiani, S.; Alibakhshikenari, M.; Falcone, F.; Limiti, E. Isolation Improvement in UWB-MIMO Antenna System Using Slotted Stub. Electronics 2020, 9, 1582. [CrossRef]

72. Sampath, R.; Selvan, K.T. Compact hybrid Sierpinski Koch fractal UWB MIMO antenna with pattern diversity. Int. J. RF Microw. Comput. Aided Eng. 2019, e22017. [CrossRef] 
73. Addepalli, T.; Anitha, V.R. A Very Compact and Closely Spaced Circular Shaped UWB MIMO Antenna with Improved Isolation. Int. J. Electron. Commun. 2019. [CrossRef]

74. Gurjar, R.; Upadhyay, D.K.; Kanaujia, B.K.; Kumar, A. A compact modified sierpinski carpet fractal UWB MIMO antenna with square-shaped funnel-like ground stub. Int. J. Electron. Commun. (AË̈) 2020, 117, 153126. [CrossRef]

75. Dey, A.B.; Pattanayak, S.S.; Mitra, D.; Arif, W. Investigation and design of enhanced decoupled UWB MIMO antenna for wearable applications. Microw. Opt. Technol. Lett. 2020,1-17. [CrossRef]

76. Alibakhshikenari, M.; Virdee, B.S.; Shukla, P.; Parchin, N.O.; Azpilicueta, L.; See, C.H.; Abd-Alhameed, R.A.; Falcone, F.; Huynen, I.; Denidni, T.A.; et al. Metamaterial-Inspired Antenna Array for Application in Microwave Breast Imaging Systems for Tumor Detection. IEEE Access 2020, 8, 174667-174678. [CrossRef] 